Published in final edited form as:

Curr Probl Surg. 1983 November ; 20(11): 687-752.

\title{
THE ECK FISTULA IN ANIMALS AND HUMANS
}

\author{
THOMAS E. STARZL, Ph.D., M.D., KENDRICK A. PORTER, M.D., and ANTONIO \\ FRANCAVILLA, M.D.
}

\section{FOREWORD}

Dr. Starzl's monograph is so extraordinary we have asked two other eminent surgical students of the portal circulation to comment. Dr. Dean Warren's appreciation precedes the monograph and Dr. William V. McDermott's critique follows it.

Mark M. Ravitch, M.D. Editor-in-Chief

\section{COMMENT}

This monograph of Eck's fistula by Starzl is the most authoritative publication since that by Pavlov and his associates in 1893. Pavlov pointed out the near-total lack of scientific data available from Eck's study, but commented that the operation would be important because it could open doors for the clarification of important problems in the pathology, physiology, and pharmacology of the liver.

No one has grasped this opportunity with the brilliance and dedication of Starzl, and in this arena he has no peers. I know of no other source from which this outstanding scientific and clinical correlation could have come.

W. Dean Warren, M.D.

\section{SELF-ASSESSMENT QUESTIONS}

1. The most important hepatotrophic hormone or substance is:
a. Phenylalanine.
b. Glucagon.
c. Epinephrine.
d. Insulin.

2. Side-to-side portacaval shunts reduce encephalopathy by maintaining partial portal perfusion of the liver. True or false?

3. Dean Warren is Dean of the following medical school:
a. Washington University.
b. Johns Hopkins.
c. Emory.
d. None of the above. 
4. The unique feature of the Warren shunt is its:

a. High flow.

b. Unusual efficiency in decompressing esophageal varices.

c. Partial maintenance of hepatopetal portal flow.

5. In animals or humans with normal livers, completely diverting portacaval shunt causes:

a. Hepatocyte atrophy.

b. Deglycogenation.

c. Reduction and disruption of rough endoplasmic reticulum.

d. Intracellular fat deposition.

6. The risks of encepalopathy after portacaval shunt are greater the more normal the preexisting hepatic function. True or false?

7. The metabolic effects of completely diverting portacaval shunt have been used to treat at least three inborn errors of metabolism. True or false?

8. Both completely diverting and selective portal-systemic shunts greatly improve the life survival curves of patients with esophageal varices. True or false?

9. Complete portal diversion causes subtle and clinically insignificant changes in a few kinds of hepatic function. True or false?

10. The liver has important and easily demonstrable immunologic functions. True or false?

Answers are found at the end of the article.

THE DUAL BLOOD SUPPLY of the liver has been known for several centuries. However, the physiologic implications of this anatomical arrangement have become intelligible only in recent years. The fact that an artery passed to the liver was never confusing, since there was no reason to suspect that it carried blood different from that pumped through other organs.

In contrast, the portal vein was suspect. Because the blood in this vessel was returning from the intestine and other splanchnic organs, it could possess nutrients or other constituents from the nonhepatic splanchnic viscera to which the liver would be exposed in high concentration on first pass. The possibility that such portal substances could be important to liver health became known as the hepatotrophic hypothesis; confirmation of this hypothesis has been one of the most important recent developments in hepatic physiology. ${ }^{1}$

The hepatotrophic concept has direct relevance to many clinical problems, including those of liver transplantation and hepatic regeneration. ${ }^{1,2}$ However, our main concern in this monograph is to explore how knowledge of hepatotrophic physiology should influence decisions about the appropriateness, timing, and type of portacaval shunt in patients with portal hypertension and esophageal varices, or in the small number of patients whose inborn errors of metabolism can be ameliorated by portal diversion.

\section{THE PORTACAVAL SHUNT (ECK'S FISTULA): A CENTURY OF CONTROVERSY}

The understanding of Eck's fistula has gone through several stages. In this discussion, the beginnings of each stage will be described in order of occurrence. Often, however, 
significant details continued to accrue for years or decades about each fundamental step. Consequently, the remarks in the following sections refer to studies widely separated in time, in some instances as much as 100 years apart.

\section{Eck versus Pavlov}

Two remarkable articles on portal physiology were published in the 19th century. Both authors were Russian. Their similarity ended there.

Nicholas Eck was a 29-year-old military surgeon without training in laboratory investigation whose unique contribution to the medical literature was an article scarcely more than 1 page long. ${ }^{3}$ In it, he cited the widespread belief that a liver deprived of its portal blood flow could not sustain life. He stated that he had overturned this erroneous opinion by constructing completely diverting portacaval anastomoses (later known as Eck's fistula) in eight dogs. Seven animals died during or shortly after the operation. The eighth recovered fully and was observed for $2 \frac{1}{2}$ months before it escaped from the laboratory, never to be found.

Eck envisioned the clinical use of his operation and gave an explicit although brief account of this technique. His purpose he described as follows:

I am conducting these experiments with the purpose of clarifying some physiologic problems as well as to determine if it would be possible to treat some cases of mechanical ascites by means of forming such a fistula. I consider the main reason to doubt that such an operation can be carried out on human beings has been removed because it has been established that the blood of the portal vein, without any danger to the body, could be diverted directly into the general circulation and this by means of a perfectly safe operation.

His optimism may have been excessive in view of the perioperative mortality of $88 \%$.

Eck concluded his article with the comment, "I had to postpone further experiments because I was called to join the active army." Although his work in surgical physiology had ended, immortality for Eck was assured. Warren ${ }^{4}$ has brought together the discoverable fragments of information about the subsequent career of this enigmatic surgeon.

The second article, published in 1893 by Hahn, Massen, Nencki, and Pawlow, ${ }^{5}$ was one of the most incisive and original contributions ever made in the field of hepatology. Pawlow (Pavlov), the senior author, was 44 years old and just becoming an international figure as the result of research on behavioral psychology and gastrointestinal physiology. His investigations were prototypic applications of the scientific method. He and his associates examined Eck's fistula in about 20 dogs. They described (complete with artist's illustrations) the primitive vascular anastomosis originally employed by Eck and in common use by the 1890s. The portal vein (or superior mesenteric vein) and the inferior vena cava were approximated with an oval row of interrupted sutures, inside of which a suture loop was inserted to permit the adjacent vessel walls to be avulsed or cut with a specially designed scissors (Fig 1).

The size of the resulting aperture was unpredictable, and consistent results by other investigators were not achieved until many years later, when the fine anastomotic techniques introduced by Carrel and Guthrie ${ }^{6}$ found their way into surgical laboratories (Fig 2). The side-to-side anastomosis of Eck's fistula was made completely diverting by tying off the portal vein superiorly (see Fig 2).

The benign nature of Eck's fistula was not confirmed by the Pavlov team. Animals with a good anastomosis had weight and hair loss. On a meat diet, they developed a neurologic disorder of ataxia and convulsions that presaged death. The syndrome was hepatic 
encephalopathy but was termed "meat intoxication," since it could be precipitated or aggravated by a meat diet. The main autopsy findings in Pavlov's animals after construction of Eck's fistula were atrophy and fatty infiltration of the liver.* Pavlov noted that these complex physiologic and morphological events did not occur or were minimized after shunt thrombosis or stenosis, or after revascularization by splanchnic collaterals of the tied-off portal vein above the site of the portacaval anastomosis. Such observations were still being made in more complicated and perhaps less convincing experiments more than 60 years later. ${ }^{8,9}$

Three quarters of a century passed before it was realized that the atrophy caused by Eck's fistula occurred with astonishing rapidity, being $90 \%$ complete within 3-4 days. ${ }^{10,11}$ In addition, the use of electron microscopy in recent years has made it possible to develop a clear picture of the organelle changes caused by portacaval shunt in the hepatocytes of previously normal rats, ${ }^{12-15} \mathrm{dogs},{ }^{10,11,, 16,17}$ subhuman primates, ${ }^{17,18}$ and humans. ${ }^{19,20}$

In all of these species the most striking and specific ultrastructural changes were depletion and disruption of the rough endoplasmic reticulum (RER) and reduction in the membranebound polyribosomes (Fig 3). ${ }^{10,11,16-18,20}$ Other features were fatty infiltration of the liver cells, a diminution in the number of glycogen granules, and deterioration of the appearance of the mitochondria. In rats, Oudea and Bismuth ${ }^{13}$ noted an increase in smooth endoplasmic reticulum (SER), but this was not prominent in dogs, baboons, or humans.

Another feature of the Eck fistula liver which escaped notice for a long time was a marked increase in hepatocyte renewal, which has been described in rats, $,{ }^{14} \mathrm{dogs},{ }^{10,11}$ and baboons. ${ }^{17,18}$ After portacaval shunt, the mitotic index and/or the rate of thymidine incorporation as measured by autoradiography rose within a few days to a new and stable level three or four times higher than the preoperative resting level. The stimulus for the lowgrade hyperplasia is unknown. It may represent a response to an increased hepatocyte death rate. Since hepatocyte hyperplasia and hypertrophy are parallel in most situations of liver regeneration, the combination of atrophy and hyperplasia after Eck's fistula is a special situation that has generated much discussion. ${ }^{11,14}$

\section{Rous versus Mann}

Peyton Rous and L.D. Larimore ${ }^{21}$ were intrigued by the possibilities that portal venous blood might contain hepatotrophic factors and that the extrahepatic diversion of these factors by portacaval shunt could be responsible for the hepatic atrophy and the poor health of animals with Eck's fistula. In 1924 they wrote, "Is the liver atrophy functional? If so, its completeness would indicate that that liver has no essential activity ... none on which its maintenance depends ... that is not intimately connected with substances derived from organs drained by the portal system." Unfortunately, their experimental models did not permit decisive experiments that might have supported these suspicions. Rous was lost to the field of hepatology when he turned his attention to oncology.

In contrast, F.C. Mann, of the Mayo Clinic, maintained an interest in hepatic and gastrointestinal physiology for his entire professional life. Mann did not believe that the portal blood had special qualities important for liver health, mainly because firm evidence to support the presence of such portal substances had never been unearthed by others or by

\footnotetext{
*Some of the earliest, if not the first, detailed illustrations of the histopathology of the dog liver after Eck's fistula were published in the Bulletin of the Johns Hopkins Hospital in 1909 by George H. Whipple and J.A. Sperry. ${ }^{7}$ Their main objective was to study chloroform intoxication, and the dogs with Eck's fistula (two in number) were part of a control group. Whipple, who became a Nobel Laureate for work in the treatment of pernicious anemia, was the founding dean of the University of Rochester School of Medicine. He died on Jan. 21, 1976, at age 97.
} 
him. ${ }^{22,}{ }^{23}$ Mann envisioned the liver mass as a byproduct of, or a kind of encrustation upon, its complex capillary bed, which in turn was controlled solely by the volume of blood presented to it. He wrote, "restoration of the liver depends ... upon the flow of portal blood through the organ [liver] and ... the primary stimulus is the [quantity of] the portal blood itself." 22 This was the flow hypothesis.

\section{The Flow Hypothesis}

The experiments of Mann merely failed to support the possibility that the portal blood has special qualities; Mann was never able to produce evidence to contradict what later came to be known as the hepatotrophic concept. In contrast, the studies by Child et al., ${ }^{24}$ using portacaval transposition in dogs as the experimental model, were erroneously but generally interpreted as crucial evidence favoring the flow hypothesis and disproving the hepatotrophic concept. By replacing the diverted splanchnic venous blood with an inflow from the inferior vena cava to the hepatic end of the portal vein (Fig 4), Child et al. avoided most of the adverse effects of Eck's fistula. These studies ${ }^{24}$ and those of Fisher and his associates ${ }^{25,26}$ gave firm support to the concept that the quality of portal venous inflow was not a prime determinant of hepatic structure, function, or the capacity for regeneration. In some of Fisher's experiments involving end points of regeneration, the diverted portal blood was replaced by arterializing the hilar portal stump. ${ }^{25}$

Subsequent workers accepted that the quantity of total hepatic blood flow was the main consideration in supporting liver health. This acceptance was maintained in spite of the demonstration that canine livers after venous transposition actually showed centrilobular atrophy, ${ }^{24}$ and major deglycogenation, ${ }^{27,} 28$ and thus were not in fact normal. The concensus favoring the flow hypothesis was an uneasy one, and in 1961 Bollman, one of Mann's younger associates, wrote, "In the 83 years since it was first reported the Eck fistula has been reasonably successful in hiding its secrets as well as giving rise to many additional questions fundamental to an understanding of the functions of the intestine, liver and brain."

\section{The Hepatotrophic Hypothesis From Studies of Liver Transplantation}

The flow-oriented view held sway until it was definitively challenged by investigations that originated in studies of experimental liver transplantation. These studies were thoroughly reviewed almost 15 years ago. ${ }^{29}$ The most illuminating observations were made when an extra liver was transplanted to an ectopic site without disturbing the animal's own liver. It was noted that auxiliary hepatic homografts underwent remarkable atrophy ${ }^{30}$ if they were revascularized by a technique described by Welch. ${ }^{31}$ With Welch's method, the auxiliary liver was provided with an arterial blood supply from the aorta or an iliac artery, and the portal vein was anastomosed to the inferior vena cava (Fig 5). The atrophy of the auxiliary organ was rapid and extreme (Fig 6), even though the blood supply was analogous to that in Child's portacaval transposition. ${ }^{24}$ One possible explanation advanced was that the animal's own liver, in situ, which was perfused first by splanchnic venous blood, was extracting a disproportionate share of unspecified hepatotrophic substances and that the auxiliary organ atrophied because of its disadvantaged competitive situation. ${ }^{30}$

The hypothesis was supported by Marchioro and his associates, ${ }^{32}$ who showed that transplant atrophy could be prevented by diverting the nonhepatic splanchnic venous blood away from the host liver and through the graft. The atrophy then affected the native liver. Confirmatory observations were reported by Thomford, ${ }^{33}$ Halgrimson, ${ }^{34}$ and Tretbar ${ }^{35}$ and their associates. Thomford et al. ${ }^{33}$ showed that atrophy in Welch's auxiliary homografts could be prevented in recipients that had undergone immunosuppression, if host livers were removed within a few days after transplantation, and Tretbar et al. ${ }^{35}$ and Halgrimson et al. ${ }^{34}$ demonstrated that the shrinkage could be reduced by diverting portal blood away from the 
host liver, even though the portal blood was not directly channeled through the transplant. Observations by Sigel and his associates ${ }^{36,37}$ with hepatic autografts implanted on intestinal vascular pedicles or directly revascularized in the neck could be interpreted in the same way.

The transplant preparations that made possible the foregoing observations had two serious flaws; these flaws prevented investigators from coming to definitive conclusions about the pathogenesis of the atrophy. First, the total flows delivered to the two coexisting livers were often different. Second, there was by definition another inherent inequality of the two organs: the homograft was usually under immunologic attack, despite host immunosuppression, ${ }^{29,} 30$ whereas the animal's own liver was not. Consequently, other experiments were undertaken that were designed to circumvent one or both of these deficiencies.

One preparation not involving transplantation was used by Marchioro and his associates $^{38,36}$ and termed a split (or partial) transposition. In essence, the procedure entailed the creation of two liver sections that differed only in the nature of their portal venous inflow. Splanchnic venous blood was provided for one portal branch to the liver, whereas the other portal branch was supplied with blood from the inferior vena cava (Fig 7); flow to the liver tissue given vena caval blood was at least as great as that on the opposite side. ${ }^{39}$ Later, Price, ${ }^{40}$ Lee, ${ }^{41}$ and Chandler ${ }^{42}$ and their associates performed analogous experiments, either with canine partial hepatic autografts or with isografts of inbred rat livers. All of these experiments showed hypertrophy in the hepatic tissue that was perfused with splanchnic blood, and atrophy in the hepatic remainder, which was provided with systemic venous inflow.

The impressive evidence obtained from 1964 to 1972 that portal hepatotrophic factors were physiologically important was not taken seriously by skeptics because of the failure to identify the mysterious portal blood substance(s). One possibility sometimes cited as an explanation for a specific benefit of portal blood was a high portal vein oxygen concentration. This concept was incorrectly attributed to Blalock and Mason, ${ }^{43}$ as we have pointed out elsewhere. ${ }^{44}$ When the oxygen content of splanchnic venous blood actually was compared to the oxygen content of inferior vena caval blood in unanesthetized awake dogs long after portacaval transposition, such an "advantage" of higher portal oxygen content did not exist. ${ }^{44}$

\section{THE HORMONAL NATURE OF THE HEPATOTROPHIC SUBSTANCES}

\section{From Double Liver Experiments}

In 1973, the explanation was advanced that endogenous hormones returning from the splanchnic organs were the principal hepatotrophic agents. ${ }^{45}$ This conclusion was based partly on the histopathologic results from another kind of "double liver" model which was used in an effort to pinpoint the splanchnic organs from which the so-called hepatotrophic factors came. Marchioro et al. used this approach in one of their auxiliary homograft experiments, ${ }^{32}$ and Pouyet et al. modified the approach in a nontransplantation model ${ }^{46}$ The most useful preparation was one in which blood returning from the pancreas, duodenum, stomach, and spleen passed to one portion of the liver while the other liver portion was perfused with venous blood returning from the small intestine (Fig 8). ${ }^{45}$

The results were unequivocal. The liver portion perfused with blood returning from the upper abdominal viscera remained healthy. In contrast, the liver portion provided with intestinal blood became atrophic, deglycogenated, and infiltrated with fat. The organelle structure of the atrophic portion was like that after portacaval shunt, including disruption and depletion of the RER. 
An accurate way to quantify hepatocyte size was developed for such experiments. ${ }^{45}$ With light microscopic tracing, hepatocytes were drawn onto a standard thickness paper and weighed. The weights were called size units. The cell size data could then be summarized in graphs or tables. In Figure 9, the right lobar hepatocytes, which had pancreaticoduodenosplenic input and so had an obvious advantage, are compared with those on the left, which were fed with intestinal venous return. The foregoing histopathologic observations made the pancreas suspect as a major hepatotrophic source and insulin the most likely principal hepatotrophic substance.

The morphological observations were bolstered by the so-called double liver preparations (see Figs 7 and 8 ) by numerous biochemical studies in the two liver sides which included glycogen, glucokinase, cyclic AMP, active phosphorylase, and lipids. ${ }^{45}$ There were major differences in the liver segments according to the nature of the portal venous inflow. The details of the biochemical disassociation are beyond the scope of this review, but the reasonable inference was that the two liver sides were living in different metabolic worlds, in which hormone control was the dominant factor. Futhermore, the nature of the biochemical differences suggested that endogenous insulin, which was being efficiently extracted by the first liver tissue to which it was exposed, played an important role. The significance of endogenous insulin was further highlighted when the advantages enjoyed by the lobes perfused by splanchnic venous blood were found to be greatly reduced, although not eliminated, ${ }^{17,47,48}$ by either total pancreatectomy or alloxan-induced diabetes (see Fig 8). These investigations, while emphasizing the role of insulin, showed equally clearly that nonpancreatic hormones or other substances also contributed to the total hepatotrophic effect of splanchnic venous blood. Although the influence of these extrapancreatic factors remains unchallenged, they have not been identified.

Complicated though they were, the double liver segment models were crucial to an understanding of the enigmatic Eck fistula. If insulin was a vital hepatotrophic factor, the reason for its unmasking by the double liver fragment experiments became understandable. The well-known efficiency of insulin removal during a first pass through hepatic tissue ${ }^{49-51}$ made the insulin relatively unavailable for a second liver or a liver segment and thus exaggerated the effect of portal blood deprivation.

At the same time, the protection afforded after portal diversion by flow augmentation procedures such as Child's portacaval transposition ${ }^{24}$ or Fisher's portal arterialization ${ }^{25}$ was explained. If insulin and other hepatotrophic substances were bypassed around a single liver they would be returned to it in a diluted form in direct relation to the total hepatic blood flow, which these procedures increased.

\section{From Hormone Infusion Experiments}

Eventually it became necessary to return full cycle back to experiments utilizing Eck's fistula. If the secrets of Eck's fistula were explained mainly by the deprivation of the liver of direct access to endogenous insulin, the experiment shown in Figure 10 should have been a direct test of that hypothesis. Nonhypoglycemic infusions of insulin, glucagon, and other substances were made for 4 days into the ligated left portal vein after construction of Eck's fistula. ${ }^{10,11}$ The experiment was designed to evaluate any direct protective effect of hormones on the left lobar hepatic tissue as well as to assess a spillover effect on the right lobes after recirculation. The results were unequivocal. Insulin greatly reduced the atrophy that otherwise halved the size of the cells within 4 days, and it preserved the hepatocyte ultrastructure. In small doses glucagon did not potentiate the action of insulin and in large doses it may have reduced the insulin benefit. Glucagon alone, in large or small doses, had no effect. ${ }^{10,11}$ 
The effect of insulin on hepatocyte proliferation in these experiments was also striking. After construction of Eck's fistula, the mitotic rate was already increased to about three times normal (from 1.6 to 4.8/1,000 hepatocytes). Insulin more than tripled this cell renewal, with no spillover to the contralateral lobes. Glucagon alone had no effect, nor did it potentiate the action of insulin. ${ }^{10,11}$

\section{From Evisceration and Hepatocyte Culture Experiments}

Thus, relative "hepatic insulinopenia" was established as the most important element in the liver injury of Eck's fistula. However, the clarity with which insulin has emerged as the principal portal hepatotrophic substance has not diminished interest in the search for contributory hepatotrophic factors. The incomplete insulin protection observed in our infusion experiments was interpreted as a reflection of the existence of ancillary substances. ${ }^{10,11}$ Evidence that there are multiple hepatotrophic factors has been uncovered with all of the experimental models used by us. ${ }^{10,11,17,45,47,48,52,53}$

However, the probability that there is multifactorial control of hepatocyte integrity has not deemphasized the central role of insulin in maintaining liver cells. This was recently demonstrated once again in animal studies after all the nonhepatic splanchnic viscera had been removed, including the pancreas. ${ }^{52,53}$ The intraportal infusion of insulin alone prevented most of the atrophy and other structural deterioration of hepatocytes that otherwise occurred, and it preserved the rate of spontaneous liver cell renewal, which was otherwise depressed. The hepatic protection in eviscerated animals ${ }^{52}$ was almost identical to that observed with intraportal insulin therapy after portacaval shunt ${ }^{10,11}$ and was indistinguishable from the hepatic protection provided by insulin in diabetic rats. ${ }^{54}$

In hepatocyte tissue culture systems, many investigators have described analogous insulin effects. ${ }^{55-58}$ The role of insulin in maintaining hepatocyte mitochondrial metabolism has also been emphasized..$^{59,60}$ No potentiating effect of glucagon has been demonstrated in any of these models.

\section{FUNCTION OF THE ECK FISTULA LIVER}

\section{Biochemical Parameters}

Liver function after construction of Eck's fistula, or after the better tolerated portacaval transposition of Child et al., ${ }^{24}$ was long thought to be essentially normal, the main defect being inefficient clearance of ammonia. ${ }^{61,62}$ Only in the last 10 or 15 years has it been realized that subtle but cumulatively massive changes in hepatic function are caused by portal diversion and for the most part by the bypassing of endogenous insulin. These alterations are so sweeping that an all-inclusive description would require a discussion of virtually every facet of hepatic physiology and metabolism.

The morphological counterpart of (and explanation for) such major changes in hepatic metabolism was described in an earlier section, when we noted that a relatively specific effect of portacaval shunt is the qualitative and quantitative loss of RER and its lining polyribosomes (see Fig 3). Since RER is the "factory" of the cell, ${ }^{63,64}$ a consequent reduction in many biosynthetic processes would be expected. Numerous studies have verified this hypothesis. We will comment here on effects chosen because of their clarity or because of their probable or proved clinical significance.

The effect of portal diversion on hepatic lipid metabolism has been unusually well studied. Since portacaval shunt reduces the serum concentration of cholesterol in animals ${ }^{17,65}$ and in humans, ${ }^{20,66}$ it was natural to wonder if this peripheral antilipidemic effect could be explained by a reduction in hepatic lipid synthesis. In our initial investigations of this 
possibility, we demonstrated reductions of more than $80 \%$ in canine hepatic cholesterol and triglyceride synthesis. ${ }^{17}$ Although a similar diminution in cholesterol and/or lipoprotein synthesis was confirmed in rats, ${ }^{67-69} \mathrm{dogs},{ }^{70}$ swine, ${ }^{71-73}$ and baboons, ${ }^{70}$ not all workers could verify these findings. The rigorously controlled studies in rats by Proia et al., ${ }^{68}$ which are the only reported animal experiments concerning Eck's fistula and lipid synthesis in which body weights were maintained or increased postoperatively, have done much to explain the discordant reports. In addition to demonstrating a reduction in cholesterol synthesis, Proia et al. ${ }^{68}$ made the crucial observation that the total body cholesterol was diminished after portal diversion. As will be discussed later, data on hepatic lipid synthesis also are available from patients treated by us with portacaval shunt for familial hypercholesterolemia. It may be considered proved that lipid homeostasis is altered to an extraordinary degree by portacaval shunt, the reduction in hepatic lipid synthesis being the greatest change.

It has been equally well established that bile acid synthesis is greatly reduced by portacaval shunt. ${ }^{68,74-76}$ Another synthetic pathway that has been well studied after portal diversion is the hepatic urea (Krebs-Henseleit) cycle, which has been shown by Reichle et al. to be depressed by Eck's fistula in rats ${ }^{77}$ and dogs ${ }^{78}$; they demonstrated a reduction in several of the enzymes involved in this metabolic pathway.

As detailed studies are made of other hepatic synthetic or metabolic processes after portacaval shunt, it will not be surprising if all are found to follow the same pattern. This possibility is supported by many studies during the past 15 years that have shown that portacaval shunt lowers the activity of the hepatic microsomal mixed-function enzyme system. ${ }^{79-86}$ Aside from illustrating the principle of a wide-ranging decline in hepatic synthesis functions after portacaval shunt, these observations are of potential specific importance because the microsomal mixed-function enzyme system, for which multiple cytochrome P-450 and P-448 species serve as terminal oxidases, metabolizes a variety of drugs and foreign chemicals as well as endogenous compounds such as steroids and fatty acids. The depression of this enzyme system with its broad-ranging functions would relate to enormous numbers of metabolic effects of portal diversion.

There is no reason to suspect that depression of the microsomal mixed-function oxidase system is caused by factors other than the loss of the hormone-rich splanchnic venous blood. Proia et al. ${ }^{86}$ have shown that the poor diet and weight loss in animals with Eck's fistula are not responsible. Furthermore, Pector et al. have shown that the hepatic alterations in the mixed-function oxidase system are the same whether the tied-off central portal vein is arterialized $^{80}$ or revascularized with systemic venous blood using the transposition technique. ${ }^{81}$ These latter experiments showed that the mere restoration of the "wrong" kind of hepatic blood flow could not prevent the changes which are specific to portal diversion. The results of Pector's experiments ${ }^{80,81}$ were predictable from the earlier work of Marchioro et al., ${ }^{39}$ in which flow augmentation with systemic venous or arterial blood did not prevent atrophy of liver tissue that had lost its portal venous inflow.

The most important single factor in the etiology of the complications of Eck's fistula is depriving the liver of direct access to endogenous insulin. In accordance with this concept, Kato ${ }^{87}$ has shown that the activity of the mixed-function oxidase system is depressed in rats with alloxan-induced diabetes in the same way as it is depressed by portacaval shunt.

\section{Questions of Immunology}

It can be considered firmly established that portacaval shunt causes many alterations in hepatic metabolism. Far more speculative is the possibility that immunologic function may be changed. 
Studies during the last 20 years have suggested, or have claimed to demonstrate that there is a reduced response to antigens introduced into the portal as compared to the response to those introduced into the systemic venous system. ${ }^{88-95}$ Partial removal of the antigens by the liver and thus a diminished host reaction to their presence has been the most common explanation. Alternatively, some investigators have suggested that antigen delivery to the liver via the portal vein could contribute to the induction of tolerance ${ }^{88,96-98}$ Many of these investigators have envisioned the normal liver as a barrier against, or as a modulator of, a host of environmental antigens, toxins, or carcinogens from the gastrointestinal tract which could injure the whole animal or the liver itself. Obviously, such a first-pass screening function would be mechanically disconnected by portacaval shunt. In addition, the depression of the hepatic mixed- function oxidase system after portacaval shunt, described in the preceding section, could further jeopardize such a guardian role.

The expectation that the liver could remove or inactivate antigens has led to efforts to create "privileged" situations with a variety of homografts. The organs used for such test systems have included kidneys ${ }^{99-105}$ and hearts. ${ }^{106}$ The venous return of the transplant in these preparations has been directed through the liver via an anastomosis to the portal vein (Fig 11). In addition, pancreatic islet cells ${ }^{107,108}$ and parathyroid cells ${ }^{109}$ have been transplanted directly into the portal circulation or into the liver.

The results have been variable. In rats, all reports have described a protective effect of the portal site, but usually only across easy histocompatibility barriers. ${ }^{105,106,108,109}$ Mazzoni et al. ${ }^{103,104}$ had similar positive results in pig kidneys, but their findings were not confirmed by Hickman and Terblanche ${ }^{101}$ or by later studies by Mazzoni himself. ${ }^{110}$ Barker and Corriere, ${ }^{99}$ Fukuda et al., ${ }^{100}$ and May et al. ${ }^{102}$ saw no amelioration of the rejection of primary canine kidney homografts drained through the portal vein.

The concept of hepatic clearance of antigens was thought by us to be so important that Mazzoni, one of the main proponents of this hypothesis, ${ }^{103,104}$ was invited to our laboratory in 1976 and 1977 to verify his own earlier observations. He was unable to do so. When he transplanted kidneys into mongrel dogs or into pigs so that the renal venous drainage was into the portal system of the hosts (see Fig 11), graft survival was not significantly increased compared to graft survival when renal venous drainage was into the vena cava. ${ }^{110}$

On the basis of Mazzoni's later investigations, ${ }^{110}$ it seems unlikely that any specific benefit from organ transplantation to the portal vein can be expected in patients. The question that remains is whether the portal site allows amelioration of rejection in rats and mice. It is unlikely that the issue of "portal" implantation will ever be important in transplantation, but the intriguing possibility that the liver is a subtle modulator of immune events has not been disproved. For the moment, however, it must be concluded that there is no sound factual basis for this concept and that a change in immunologic reactivity is not, therefore, an expected consequence of portacaval shunt.

\section{RELEVANCE OF ANIMAL STUDIES TO HUMAN PHYSIOLOGY}

The histopathologic alterations in, and changes in function of, the liver caused by portacaval shunt are essentially the same in rats, swine, dogs, monkeys, baboons, and humans. ${ }^{18}$ However, until about 30 years ago it was not known whether the lethal consequences of portacaval shunt represented more than a species peculiarity of the dog. Until then, Eck's fistula had not been evaluated in other animals. In humans, portacaval shunt had not been performed on anybody who had a previously normal liver, and consequently any opinions about the metabolic effects of Eck's fistula in man were purely speculative. The dearth of information began to end with the classic clinical articles of McDermott et al., 111,112 which seemed to be confirmed by Hubbard ${ }^{113}$ a few years later. Unfortunately, misinterpretation of 
the observations in these reports actually delayed an understanding of the physiology of human portacaval shunt for almost two decades.

\section{The McDermott-Hubbard Artifact}

McDermott et al. ${ }^{111,112}$ and Hubbard ${ }^{113}$ each reported on two patients who had carcinomas of the head of the pancreas and grossly normal livers except for biliary obstruction. In order to perform pancreaticoduodenectomy, it was necessary to resect the portal vein, and in all four patients, the end of the transected superior mesenteric vein was anastomosed to the side of the inferior vena cava.

The results were devastating. Within a few weeks or months, all four patients developed episodic hepatic encephalopathy, malnutrition, fatty infiltration of the liver, and hypoalbuminemia. When the patients died, 4-20 months postoperatively, all were tumor free. It was concluded that these were examples of Eck's fistula in humans with normal livers, that humans were even more sensitive than dogs to the metabolic complications of Eck's fistula, and that the ability of patients to tolerate portal diversion was inversely related to the quality of preexisting hepatic function.

None of these conclusions was valid. The errors were caused by the investigators' failure to appreciate that the operations were not pure Eck's fistulas. In addition to the portal diversion, all four of the patients also had removal of variable amounts of the pancreas, which later investigations proved to be the single most important source of hepatotrophic substances. Eventually it was realized that man is less, not more, susceptible than experimental animals to the metabolic complications of Eck's fistula. Finally, it is not true that portacaval shunt is tolerated best in patients with the worst hepatic disease; the converse is true.

\section{The Species Factor in Encephalopathy}

The weight loss, alopecia, and encephalopathy first described in dogs after portacaval shunt construction have been less severe or inconstant in rats. ${ }^{114-117}$ In swine, some investigators have been able to carry out studies for 2-4 months after portacaval shunt construction, ${ }^{71-73}$ but others have found the operation to cause hepatic failure and encephalopathy within days. ${ }^{118,119}$ Subhuman primates including Rhesus ${ }^{120}$ and Macaca mulatta ${ }^{121}$ monkeys as well as baboons, ${ }^{17,} 18$ may develop the Eck fistula syndrome in such a fulminant form as to make it difficult to perform metabolic studies. The brains of the baboons have shown the same glial proliferation and central pontine myelinolysis ${ }^{18}$ seen in rats ${ }^{117}$ and monkeys ${ }^{122}$ after portal diversion.

Fortunately, the remarkable encephalopathic complications produced after the subhuman primate operations have not been duplicated in humans with previously normal livers. The human experience with pure Eck's fistula in the presence of normal hepatic function has been in patients with types I, III, and VI glycogen storage disease (GSD) or familial hypercholesterolemia $(\mathrm{FH})$.

The patients with GSD generally tolerated portacaval shunt well in spite of the fact that their well-functioning livers usually had significant preexisting structural abnormalities. ${ }^{19,} 66$ Of nine GSD patients followed by us for $43 / 4$ to $191 / 2$ years after portal diversion, only one developed hepatic insufficiency and encephalopathy -8 years after portacaval shunt. This girl was successfully treated with orthotopic liver transplantation ${ }^{123}$; it was possible to take down the portacaval anastomosis and use the portal vein to revascularize the new liver. None of the other patients with GSD treated with portal diversion are known to have developed encephalopathy. 
The picture was even clearer in patients who had portacaval shunts constructed for FH. Characteristically, patients with this disease start with completely normal liver structure and normal hepatic function. Only one of our 13 patients, and none of the 26 others reported from other centers, ${ }^{124}$ had overt manifestations of the Eck fistula syndrome on follow-up of 1 to nearly 10 years. The exception in our series was a 3 -year-old girl who had a single episode of unconsciousness 9 months after portacaval shunt construction at a time when the blood ammonia was $85 \mu \mathrm{g} / \mathrm{dl}$ (normal in that laboratory, $<55 \mu \mathrm{g} / \mathrm{dl}$ ). Encephalopathy was accepted as the diagnosis because no other explanation was found. The child is well on a low-protein diet.

The histopathologic changes caused by portal diversion in the livers of these patients (see Fig 3) have been indistinguishable from those in animals. ${ }^{20,}{ }^{124}$ It is noteworthy that blood ammonia levels, when measured, have always increased to or beyond the upper limits of normal ${ }^{124}$; low-grade elevations of serum transaminase and alkaline phosphatase levels have been common. Although the patients have been clinically well and on a normal diet after portacaval shunt construction, there has been no reason to doubt that their hepatic function has been impaired. Nevertheless, their behavior and physical development have not been obviously altered.

The only other use of portal diversion in the presence of a normal or nearly normal liver has been in patients with esophageal varices from extrahepatic portal venous obstruction (presinusoidal block). The thrombosed portal vein in many such patients is replaced with a multitude of collaterals which are frequently so well developed that they have been referred to collectively as "cavernous transformation." It has been suspected for a long time, and unequivocally demonstrated in a recent publication of Warren et al., ${ }^{125}$ that flow in the collaterals is hepatopetal and thus important in perfusion of the liver with hormone-rich splanchnic blood, albeit by circuitous routes. If a sound portal-systemic anastomosis can be constructed (usually with splenorenal, cavomesenteric, or makeshift shunts), control of variceal hemorrhage is almost always achieved. At the same time, the collateral splanchnic venous flow to the liver described above is "stolen" from the liver through the shunt. ${ }^{125}$

In spite of this physiologic penalty, clinical results after technically satisfactory shunt procedures usually have been good, as exemplified by a recent report of Grauer and Schwartz. ${ }^{126}$ Of their 19 patients, none developed liver failure or encephalopathy on followup as long as two decades. The observations were consonant with those of previous workers. ${ }^{127,128}$

Even more reassuring were the results obtained in the French hepatology unit of Alagille and summarized by Alvarez et al. ${ }^{129}$ Seventy-six children with portal obstruction had portalsystemic shunts (32 central splenorenal, 32 Marion mesocaval, 6 interposition mesocaval, 3 makeshift, 2 distal splenorenal, 1 portacaval). Seventy of the shunts remained patent. Although blood ammonia levels were slightly elevated, none of the patients developed encephalopathy, as judged by neurologic examinations and electroencephalograms every 612 months, and by analysis of academic performance. Physical growth was not interrupted; in fact, it was accelerated.

Nevertheless, hepatic dysfunction and encephalopathy have been reported by Mikkelsen et al. ${ }^{130}$ with or without portal diversion in patients with extrahepatic portal block; in two such patients Warren et al. ${ }^{125}$ achieved reversal of encephalopathy after disconnecting the portalsystemic shunts and restoring the hepatopetal flow.

Voorhees et al. ${ }^{131}$ have added the chilling note that patients treated with portal-systemic shunt for extrahepatic portal block at Columbia University, New York, have had a high incidence of psychological and psychiatric perturbations, which they suggested might be 
occult manifestations of encephalopathy. These latter conclusions have not been verified, and careful psychological and intelligence examinations in patients with familial hypercholesteremia ${ }^{124}$ have not turned up anything resembling Voorhees' observation.

The resistance of man to encephalopathy after portacaval shunt has not been explained satisfactorily. One possibility is that the natural diet of humans is more compatible with the depressed hepatic function of Eck's fistula than the diet of some of the animal species. In various animals, the clinical manifestation of hepatic encephalopathy can be forestalled or ameliorated with special low-protein diets, and obviously the same kind of dietetic management is a standard reaction if hepatic encephalopathy occurs in patients.

\section{The Human Eck Fistula Syndrome versus Preexisting Liver Function}

The McDermott-Hubbard artifact led to speculation, if not to an absolute conviction, that the risks of the Eck fistula syndrome in humans were proportionate to the quality of preexisting function, being greatest with a completely normal liver. It was rationalized that severely diseased livers that had already lost hepatopetal portal flow to collaterals would not be much further affected by a portacaval shunt and that such livers would have had compensatory increases in hepatic artery flow. In contrast, the argument continued, normal or near-normal livers that still retained significant portal venous flow would sustain a major insult by abrupt diversion of this flow.

It would be a perversion of scholarship to cite statements by distinguished hepatic surgeons who have defended this kind of sophistry during the last 30 years. Suffice it to say, during much of this same period the inescapable conclusion from clinical experience with various shunting procedures has been the opposite of the foregoing hypothesis. For two decades, the risk in most patients being considered for portal diversion has been stratified, by the socalled Child classification, according to the quality of hepatic function. ${ }^{132}$ Patients with the best hepatic function are placed into Child class A, those with the worst function are placed into class $\mathrm{C}$, and the others are placed in class B. All major studies that have taken into account such disease staging have shown the best results after portal-systemic shunt operations to be in class A patients and the worst to be in class C patients. Parenthetically, the Child class A patients are the most apt to have residual hepatopetal flow, although the association is too imperfect to be useful in predicting the outcome. ${ }^{133,134}$

\section{ECK'S FISTULA FOR METABOLIC OBJECTIVES IN HUMANS}

Benefits have been seen after end-to-side portacaval shunt in patients with three inborn errors of metabolism: glycogen storage disease (GSD), familial hypercholesterolemia (FH), and $\alpha_{1}$-antitrypsin deficiency. In each instance, the amelioration of symptoms has been the tradeoff for the hepatic damage caused by putting the liver into the portoprival state.

\section{Glycogen Storage Disease}

When portal diversion was first performed for GSD almost 20 years ago, ${ }^{28}$ the rationale for the procedure was different from our understanding today. In 1963 it was hoped that by short-circuiting splanchnic venous blood around the liver, glucose would be made more readily available to peripheral tissues, with relief of hypoglycemia; it was further expected that the liver would be coincidentally deglycogenated, since this had been observed in animals. ${ }^{27,} 28$ As this monograph has made clear, the consequences of portacaval shunt are more subtle and wide ranging than the simplistic view suggested.

The first patient who had total portal diversion is still alive almost 20 years after portacaval transposition. She had type III GSD. A patient similarly treated by Riddell et al. ${ }^{135}$ also survived long term. Our second patient died 2 days after portacaval transposition, probably 
because the liver could not transmit the high-volume flow of the inferior vena cava. ${ }^{19}$ Simple end-to-side portacaval shunts were used in all of the eight subsequent patients in our series, ${ }^{19,66}$ of whom seven are alive after $6 \frac{1}{2}$ to more than 10 years.

The amelioration of symptoms of GSD was confirmed by other observers, whose cases have been summarized bv us ${ }^{19,66}$ and by other reviewers. ${ }^{136,137}$ In 1972, Folkman et al. ${ }^{138}$ added an important therapeutic dimension by showing how preoperative parenteral hyperalimentation could reduce the operative risk by normalizing preexisting hepatomegaly, acidosis, and other abnormalities, including hvperlipidemia. In an extension of this concept, Greene et al. ${ }^{139}$ and Crigler and Folkman ${ }^{140}$ showed that continuous or frequent feeding (including overnight alimentation) is more than an alternative to portacaval shunt in the treatment of this disorder-it is, rather, the therapy of choice. Nevertheless, follow-up of the early patients with GSD treated with portal diversion is of considerable interest.

The ages of our ten patients, types of disease, and symptoms are summarized in Table 1. Type I disease (glucose-6-phosphatase deficiency) was the most common indication for treatment, with type III disease (amylo-1,6-glucosidase deficiency) being a distant second.

Metabolic Effects-After portal diversion, most of the children who had preexisting hypoglycemia did not have relief of this symptom or the relief was not complete. Thus, night feedings usually had to be continued. Studies of plasma insulin and glucagon in several of these patients revealed the pattern shown in Figure 12. The flat peripheral insulin curves typical of type I GSD ${ }^{141}$ became elevated after portacaval shunt, and there were smaller increases in glucagon. The glucose tolerance curves were much the same before and after operation.

Liver glycogen concentrations in those of our patients who later had liver biopsies were not changed, nor were the measures of enzyme activity. It is of interest that Corbeel et al. ${ }^{137}$ of Belgium found a striking increase of active glucose-6-phosphatase after portacaval shunt in a child with type Ib GSD. It was speculated that the portal diversion had unmasked a nonfunctional glucose-6-phosphatase by improving the defective transport of this enzyme across microsomal membranes.

In spite of failure to alter the hepatic glycogen concentration, ${ }^{19,66}$ the liver size in several of our patients and those reported by others underwent a very obvious reduction, as measured by liver scan planimetry. Even if obvious gross shrinkage did not occur, postoperative biopsies always showed a diminution in individual hepatocyte size 19,66 similar to that produced in animals by portacaval shunt.

In contrast to the incomplete relief of hypoglycemia, all components of the hyperlipidemia which is a characteristic of the type I disease were profoundly and permanently relieved (Fig 13). Correction of other metabolic defects was observed, including abnormal bleeding, uric acid elevations, and abnormal calcium metabolism. ${ }^{19,} 66,135-138$

Growth-All ten of our patients had growth retardation before portacaval shunt. Afterward, height increases, which in most cases had virtually ceased, occurred during the first postoperative year at the rates listed in Table 2 , approximately $0.5 \mathrm{~cm} / \mathrm{month}$. The same phenomenon has been described in almost all of the other reported cases.

Quantitative measures of growth were obtained with radiographic techniques. ${ }^{19}$ An example of the results is shown in Figure 14. Comparison of the wrists and hands in this 7-year-old, stunted child before and $11 \frac{1}{2}$ months after operation shows the phenomenal effect of bone age doubling. In addition to the changes in bone size, mineralization occurred, and new wrist 
bones appeared. Circulating somatotropin in these patients was normal. ${ }^{19}$ The growth spurts may have been at least partially attributable to the increased insulin distribution to the periphery, mentioned earlier (see Fig 12), since insulin has been recognized as a major growth hormone, comparable in potency to somatotropin.

Morbidity from Portacaval Shunt-The patient who exhibited hepatic encephalopathy 8 years after end-to-side portacaval shunt for type I GSD also developed multiple filling defects in her enlarged liver. When the diseased liver was replaced at transplantation, all of the metabolic abnormalities of type I GSD were completely relieved. ${ }^{123}$ It has been proved from the study of more than a half-dozen liver-based inborn errors of metabolism that the phenotype of the transplanted organ permanently retains its original donor specificity. ${ }^{142}$

One other child developed a blood ammonia concentration of $85 \mu \mathrm{g} / \mathrm{dl}$ (normal, $<60 \mu \mathrm{g} / \mathrm{dl}$ in that laboratory), but there were no symptoms of encephalopathy. This patient died almost 5 years after portacaval shunt construction during an attempt at transcaval radiographic visualization of the portacaval anastomosis. Except for the slightly elevated blood ammonia concentration, standard liver functions were normal. At autopsy the liver showed macroadenomatosis, very similar to that in the child who underwent liver transplantation. An autopsy finding that had not been suspected in life was advanced right ventricular hypertrophy and dilatation. The smaller pulmonary arteries and arterioles showed medial muscle hypertrophy, medial and intimal fibrosis, scattered fibrinoid necrosis, and numerous plexiform lesions. Such cardiopulmonary complications have been documented in other patients with type I GSD and other liver diseases. ${ }^{143}$ This complication did not have an obvious relationship to the portacaval shunt. The macroadenomatosis seen in these patients is very common in patients with type I GSD and was recently reported in seven of eight nonshunted patients, aged 3-28 years. ${ }^{144}$

The Present Status of Portal Diversion-Portacaval shunt in the treatment of GSD has been supplanted by the continuous night feeding schedule advocated by Greene et al. ${ }^{139}$ Portacaval shunt, if it has any role at all, is reserved for failures of this more conservative and liver-sparing approach. We have not performed a portacaval shunt for GSD since October 1976.

\section{Familial Hypercholesterolemia}

In March 1973, a 12-year-old girl with homozygous FH was treated with an end-to-side portacaval shunt; her serum cholesterol concentration fell markedly. ${ }^{20}$ In patients with this disease, there is an absence or deficiency of cell membrane lipoprotein receptors ${ }^{145,} 146$ and thus no "switch-off" mechanism to control lipid (especially cholesterol) synthesis.

By the summer of 1982, 12 patients with FH had been treated by us in this way. Eight of the patients were children, aged 2-14 years. The four adults were aged $21,31,37$, and 52 years. All but two were homozygous for the FH abnormality. Low-density lipoprotein (LDL) receptors were determined by Goldstein and Brown ${ }^{145}$ on cultured fibroblasts obtained from all patients and many of their close relatives. Nine of the ten patients with homozygous disease were LDL-receptor negative and the other was LDL-receptor defective. Two of the patients had heterozygous disease.

The portacaval shunts were constructed by anastomosing with fine continuous suture the cut end of the portal vein to an elliptical defect in the anterior or anterolateral wall of the suprarenal inferior vena cava. Tributaries to the portal vein above the site of its transection were looked for and ligated. The anastomoses were made slightly larger than the natural diameter of the portal vein. Although hypercoagulability has been described in $\mathrm{FH},{ }^{147}$ no anticoagulants were given during or after operation. Thrombosis after portacaval shunt in 
children with portal hypertension has been so high that most pediatric surgeons prefer to use the operation only in patients older than 8 or 10 years and in those whose anastomoses can be made at least $1 \mathrm{~cm}$ in diameter. ${ }^{127,} 148$ Although these minimum conditions did not obtain in the majority of our patients, there were no thromboses and no deaths.

Effect on Serum Lipids-Total serum cholesterol concentrations fell significantly in every patient after portacaval shunt. ${ }^{124}$ When measured, LDL cholesterol levels were reduced commensurately. The total cholesterol values declined 20\%-55.4\% (average, $33.8 \%$ ), and this decline was maintained throughout the period of study. HDL cholesterol and triglyceride levels were variably effected. Tendinocutaneous xanthomas regressed or disappeared in every patient (Fig 15).

Experience of Others in Treating FH-The consistency of the anticholesterolemic response was greater in our patients than in patients treated by others. There are reports on a total of 26 additional patients, 13 of whom were treated in Johannesburg. ${ }^{149}$

In the 13 patients treated elsewhere than in Johannesburg, ${ }^{150-57}$ serum cholesterol reductions of at least $30 \%$ were obtained in ten, as well as regression of tendinocutaneous xanthomas to the same extent as originally reported by us..$^{20,158}$ In two of the three exceptional patients, shunt thrombosis was proved, ${ }^{151}, 152$ and in one of these the cholesterol level fell by $40 \%$ after a later mesocaval shunt. ${ }^{152}$ In the third patient, described by Soutar, My ant, and Thompson, ${ }^{154}$ there was presumptive but not definitive evidence of shunt occlusion. The cholesterol level, after an early fall of $40 \%$, returned several months later to near preoperative values. At the same time, initially elevated serum glucagon levels, which are typically found with a patent shunt, ${ }^{74,159}$ fell to baseline.

The early 160 and subsequent ${ }^{149}$ reports from Johannesburg have confirmed the value of portacaval shunt in FH but have provided minimal incentive for expanded trials. Of 13 homozygous patients with unstipulated membrane receptor status, one died 2 days postoperatively of a myocardial infarction. The remaining 12 had significant but often modest falls in serum total and LDL cholesterol levels, and the values later returned to or toward preoperative levels in three. Xanthomas regressed in eight patients, were stable in two, and increased in two. Almost all patients developed postoperative splenomegaly, a finding compatible with sluggish or obstructed splanchnic venous drainage or, alternatively, with a manifestation of FH that previously had not been appreciated. ${ }^{149}$

A full explanation for the indifferent results in the Johannesburg series has not been forthcoming, but possibilities discussed elsewhere ${ }^{124}$ include a high incidence of shunt thrombosis or ineffective portal diversion, peculiarities of the FH endemic to that region of South Africa, or other less obvious factors.

The invariable and long-lasting lipid lowering in our 12 patients was achieved without surgical morbidity. The physical development of children who were normal before operation has proceeded, and the growth of those who were stunted before operation has moved toward normal. As described in an earlier section, emotional or intellectual deterioration secondary to the portal diversion has not occurred, although one child had an acute episode of encephalopathy which was managed with diet.

Mechanisms of Lipid Lowering-The mechanisms causing lipid lowering in patients with FH probably are qualitatively similar to those in experimental animals, discussed earlier in this monograph. 
Data relevant to mechanisms in humans with FH are also available. Soutar et al. ${ }^{154}$ found no change in LDL synthesis and an actual rise in very-low-density lipoprotein (VLDL) synthesis in the patient discussed earlier whose shunt may have closed. Strikingly different conclusions were reached after metabolic studies in three of the 12 patients of our own series. In our patient 2 , Bilheimer et al. ${ }^{74}$ showed that cholesterol and LDL synthesis, which were inappropriately high before portacaval shunt, were reduced afterward by $62 \%$ and $48 \%$, respectively. The fractional catabolic rate, which was only a third of normal at the outset, as is typical for FH, fell further after operation. Ginsberg et al. ${ }^{161}$ studied the heterozygous patient 6 in our series; that patient responded to portal diversion with major reductions in LDL as well as VLDL apoprotein-B synthesis, in VLDL triglyceride synthesis, and in the already subnormal fractional catabolic rate.

The extraordinary degree to which cholesterol homeostasis was altered by portacaval shunt in the homozygous patient 4 in our own series and the heterozygous patient 6 has been described by McNamara et al. ${ }^{75}$ Exogenous cholesterol absorption was unchanged in both patients, and bile acid synthesis was halved. Whole body cholesterol synthesis was decreased by $68 \%$ in patient 4 and by $41 \%$ in patient 6 . The total body cholesterol mass $1 \frac{1 / 2}{2}$ years after portacaval shunt was reduced by $59 \%$ in patient 4 and by $43 \%$ in patient 6 . These data are compatible with the extraordinary diminution or disappearance of tendinocutaneous xanthomas (Fig 15) and with the hope that the lethal cardiovascular complications of FH can be slowed or forestalled by portacaval shunt.

Effect on Cardiovascular Disease-The degree to which the cardiovascular complications of FH can be relieved or prevented by portal diversion has not been established. Reversal of aortic stenosis was seen in two of our patients, but regression of atheromas in the coronary arteries and aorta was not regularly achieved. ${ }^{124}$ Small and Shipley ${ }^{162}$ have examined factors that could preclude the reversal of atherosclerosis, and some of these, including secondary fibrosis, would not be corrected completely by the resorption of intravascular xanthomas. Farriaux et al. ${ }^{163}$ have suggested that anatomical stabilization of the vascular disease may be the best that can be achieved with a portacaval shunt, even in patients whose angina pectoris is relieved. Experience in several patients at our center and elsewhere ${ }^{124,153,157}$ has shown the value of aggressive surgical correction of technically remedial cardiovascular lesions in combination with portal diversion. Of greater importance will be the implementation of aggressive therapy at a young age, before irreversible cardiovascular complications develop. In patients with FH who are refractory to therapy with diet and medications, portacaval shunt may be the treatment of choice. Postoperatively, medications and diet should be tried again, since further declines in postshunt cholesterol levels have been seen using diet and medications which had previously been ineffective.

The staged combination of portacaval shunt and the ileal bypass procedure of Buchwald et al. ${ }^{164}$ has been tested in three patients. The combination had an apparently additive effect, ${ }^{149,} 156$ even though ileal bypass alone has little or no effect on homozygous FH. ${ }^{164}$ In dogs, Guzman et al. ${ }^{165}$ have noted an additive effect of portal diversion (by portacaval transposition) plus ileal resection. Efforts by us ${ }^{166}$ to document a complementary effect of ileal resection and portacaval shunt in dogs failed to confirm the claims of Guzman et al., ${ }^{165}$ and a subsequent report by Rucker et al. ${ }^{167}$ from the Minnesota study has shown that the additive effect originally reported by Guzman was not sustained.

Limitations of Portacaval Shunt-Portacaval shunt, with or without supplementary treatment, is only palliative in patients with FH. The amelioration of the abnormal metabolic patterns of FH has derived from the countervailing and potentially dangerous hepatic abnormalities caused by portacaval shunt (see Fig 3 ). The palliation has been incomplete, 
since restoration of normal serum cholesterol values has not been achieved in any patient with homozygous disease. Because of the evidence of a central hepatic role in the regulation of lipid metabolism, ${ }^{168-171}$ it is possible that the metabolic abnormalities of $\mathrm{FH}$ could be rectified by the ultimate step of liver transplantation.

\section{Portal Diversion for $\boldsymbol{\alpha}_{1}$-Antitrypsin Deficiency}

In both GSD and FH, the generally adverse effects of portal diversion have been accepted as the price for improvement of even more serious metabolic perturbations. There is a possibility that a third inborn error, $\alpha_{1}$-antitrypsin deficiency, may be added to this list. ${ }^{172}$

Patients with this disorder have a low level of plasma $\alpha_{1}$-antitrypsin (an $\alpha$-globulin) and a high incidence of pulmonary complications. ${ }^{173}$ In 1969, Sharp et al. ${ }^{174}$ demonstrated a variable association of the $\alpha_{1}$-antitrypsin deficiency with liver disease, an observation that has had overwhelming confirmation. ${ }^{175,176}$ It is now accepted that $\alpha_{1}$-antitrypsin deficiency is a common cause of chronic liver disease both in the pediatric and in the adult populations.

The probable pathogenesis of the liver disease has been recently reviewed. ${ }^{177}$ In essence, the basis for the liver injury may be the hepatic production of an abnormal $\alpha_{1}$-antitrypsin which cannot be effectively transported out of the liver cells and which consequently becomes sequestered within the hepatocytes near the RER. Irritation by the entrapped glycoprotein has been postulated as the cause of the hepatic cirrhosis, portal hypertension, and hepatic failure that follow. The progressive and inexorable course that this pathogenesis implies may have discouraged attempts to treat complications of the portal hypertension (such as variceal hemorrhage) with portal-systemic shunts. In addition, the results with portal diversion have been poor. ${ }^{178-180}$ Only Sotos et al. ${ }^{181}$ have reported encouraging results, and their observations were limited to two children.

We have performed end-to-side portacaval shunt in three children with the cirrhotic liver disease of $\alpha_{1}$-antitrypsin deficiency. ${ }^{182}$ The first two patients had major hemorrhages from esophageal varices. The third had ascites, but the principal reason for operation was the hope of influencing the metabolism of the $\alpha_{1}$-antitrypsin.

Follow-up data of $3 \frac{1}{2}, 5$, and nearly 7 years are available. ${ }^{182}$ Standard liver function tests have not changed greatly since the portacaval shunt, although the plasma ammonia levels have been elevated in both patients in whom measurement was systematically made. None of the three patients have had symptoms of encephalopathy, although patient 2 had mental slowness for the first 2 years after operation.

The possibility that the liver damage of $\alpha_{1}$-antitrypsin deficiency can be slowed by portacaval shunt has been emphasized by the stabilization in all three patients of a previously deteriorating clinical state. However, the most objective evidence that the natural history of the disease was favorably altered by portacaval shunt came from the histopathologic studies of biopsy specimens obtained operatively and postoperatively in patients 2 and $3 .{ }^{182}$ In patient 2, a biopsy specimen obtained 9 months after the portal diversion showed a reduced number of hepatocytes containing $\alpha_{1}$-antitrypsin globules$28.5 \%$, compared to $38.2 \%$ at the time the portacaval shunt was constructed. The hepatocytes were $22 \%$ smaller, and the amount of RER in their cytoplasm was greatly reduced.

In patient 3 the percentage of hepatocytes containing $\alpha_{1}$-antitrypsin globules was $44.5 \%$ at the time of operation and $48.2 \%$ and $38.7 \%$ at 7 and 13 months, respectively, after portacaval shunt. The hepatocytes were $15 \%$ and $20 \%$ smaller at these postoperative followup times. The percentage of hepatocytes containing $\alpha_{1}$-antitrypsin globules was reduced to 
$20.4 \%$ in the biopsy specimen obtained 35 months postoperatively. The hepatocytes remained 20\% smaller than in the preoperative biopsy specimen, and the amount of both RER and SER in their cytoplasm was reduced. The severity of the macronodular cirrhosis was unaltered.

We assume that the portacaval shunt diminished the synthesis of the abnormal $\alpha_{1}$ antitrypsin, presumably by altering the function of the RER and its ribosomes (see earlier section on hepatic function after construction of Eck's fistula) without commensurately reducing the transport of this glycoprotein. ${ }^{172,182}$ With a better equilibrium between the production and transport of the $\alpha$-globulin, it is possible that its intracellular accumulation has been slowed or probably even reversed.

\section{PORTAL-SYSTEMIC SHUNT FOR COMPLICATIONS OF PORTAL HYPERTENSION}

We have emphasized the morphological and metabolic changes caused by portal diversion and the explanations for these wide-ranging effects. The inescapable conclusion from all of the work on this subject in the last decade is that portal-systemic diversion is so inherently harmful to the liver that it should be considered only for life-threatening disease conditions or complications. Exploitation of portal diversion for its increasingly well-understood metabolic effects, as described in the preceding section, has been a recent development and one that is still in evolution. In contrast, there is little new of a conceptual nature that can be written about the use of portal-systemic shunting for mechanical and hemodynamic objectives, except for the contributions of W. Dean Warren and his associates.

As mentioned at the outset, Eck envisioned the use of portacaval shunt for the treatment of hepatogenic ascites. ${ }^{3}$ In their historical treatise, Donovan and Covey ${ }^{183}$ described how other surgeons interested in the procedure realized that it also might be a way to control hemorrhage from esophageal varices. Vidal ${ }^{184}$ was probably the first (June 1903) to construct a portacaval shunt successfully. His patient, a 34-year-old alcoholic man, had ascites and a 7-week history of recurrent variceal hemorrhages. He survived more than 3 months after operation.

Both of the principal complications of portal hypertension, ascites and hemorrhage, have been extensively treated by a variety of portal-systemic shunts since Whipple ${ }^{185}$ and Blakemore and Lord ${ }^{186}$ ushered in the modern era of this field not quite 40 years ago. Although portal diversion often dries up ascites, its use for this purpose has been all but abandoned because of the mortality and morbidity (especially encephalopathy) of the procedures, because better diuretics have made ascites easier to control, and because the safer peritoneal-venous (LeVeen-type) shunts can be used if nonoperative care is unsuccessful. ${ }^{187}$

The boom in portal-systemic shunts to control variceal bleeding has lasted longer, but such procedures are being recommended far less frequently today than they were a few years ago. The downward trend undoubtedly will continue, for several reasons. The developments in hepatotrophic physiology summarized in this monograph have shown how destructive to the normal liver portal diversion can be. The incongruity of deliberately imposing such an insult on an organ already abnormal and laboring under the handicap of intrinsic parenchymal disease has not escaped the attention of thoughtful clinicians. Furthermore, the results of randomized clinical trials during the last 20 years, in patients with or without previous variceal hemorrhage, have not demonstrated a statistically significant increase in survival after any kind of portal-systemic shunt compared to that achievable without operation. ${ }^{188-194}$ The decrease in mortality from gastrointestinal hemorrhage after shunting 
has been canceled by perioperative deaths and/or by a higher subsequent death rate from hepatic failure. Consequently, alternative methods to control variceal bleeding without changing the preexisting hepatic blood flow patterns have been viewed with increasing interest. The most promising techniques are sclerotherapy of the varices ${ }^{195-197}$ and transhepatic embolism of the left gastric (coronary) vein. ${ }^{198,} 199$

The growing nihilism about portal diversion in patients with advanced hepatic disease will be justified to the extent that liver transplantation becomes an option in future years. An existing shunt, or for that matter, any kind of previous upper abdominal operation, is an extremely negative factor in a patient being considered for hepatic transplantation, ${ }^{142}$ and may preclude such transplantation.

In the meantime, a limited number of patients will be bonafide candidates for portalsystemic shunts. Available shunting techniques are illustrated in Figures 16 and 17. The literature on the various shunt operations is so voluminous and so frequently contradictory that no effort is made to review it here. The interested reader can quickly obtain a relatively complete idea of what has been written by perusing any one of three recent reviews. ${ }^{200-202}$

\section{Portal Flow Studies in Shunt Planning}

A logical decision about the type of shunt to be used cannot be made without ascertaining whether there is still perfusion of the liver by portal blood (hepatopetal flow). Although there is no completely accurate technique to obtain this information, rough estimates of residual portal flow can be made with late phase venograms after selective celiac or superior mesenteric arteriography, ${ }^{203,204}$ or by direct dye injection into the splanchnic venous system using splenoportography, ${ }^{205}$ transhepatic portography, ${ }^{206}$ or umbilical venography. ${ }^{207}$ A more quantitative estimate may become a practical objective in the future. Rikkers, Miller, and Christian ${ }^{208}$ have described a radiocolloid technique for quantifying the fraction of superior mesenteric venous blood that perfuses the hepatic sinusoids.

The concept of using this kind of hemodynamic information for preoperative assessment can be traced back through the literature for several decades, particularly in the publications of Womack and his associates, ${ }^{209,210}$ but its general acceptance came from the brilliant studies of Warren, Zeppa, and Fomon, ${ }^{211}$ published in 1967. The Warren-Zeppa-Fomon article was the first step toward the increasingly accepted objective ${ }^{212}$ of decompressing esophagogastric varices without paying the penalty of hepatic portal flow deprivation.

\section{Completely Diverting Shunts}

End-to-Side Portacaval Shunt-The standard shunt against which all other shunts must be compared is the end-to-side portacaval shunt (see Fig 16,A). With this operation, complete portal diversion is achieved quickly, easily, and with very little blood loss; the portal diversion is the same as that achieved with a well-constructed Eck's fistula in animals. Because pressure in the splanchnic venous system is reduced, hemorrhage from esophageal varices is practically eliminated. This is the sole benefit from the operation, with the possible exception of relief of ascites.

The other effects of the operation are predictably adverse. The loss of liver perfusion with hepatopetal portal venous blood, in those patients still possessing such a flow, immediately puts the patient at potential risk of the portoprival (Eck fistula) syndrome. Undoubtedly, the resulting encephalopathy is mainly a reflection of diminished hepatic function. In addition, Price, ${ }^{213}$ Harrison, ${ }^{214}$ and Rikkers ${ }^{215}$ and their associates have reported that the low venous pressure in the splanchnic bed after portacaval shunt can contribute to increased absorption of metabolites, intestinal toxins, and probably ammonia. This "low-pressure" absorption 
factor was recognized by Warren et al. more than 15 years ago, ${ }^{211}$ as well as recently, ${ }^{212}$ as a possible ancillary mechanism for the high incidence of encephalopathy seen after construction of completely diverting end-to-side or side-to-side portacaval shunts.

Side-to-Side Portal-Systemic Shunts-The side-to-side shunts are constructed with portacaval, cavomesenteric (Marion-Clatworthy), mesocaval, or conventional splenorenal anastomoses (see Fig 16,B). These shunts were once thought to yield different results than the end-to-side shunts; it was assumed they did not completely eliminate portal perfusion. However, all effective side-to-side shunts are merely variants of a common theme, as shown in Figure 16,B: all of the blood returning from the distal splanchnic bed, as well as a variable amount from the sinusoids of the liver itself, can pass into the systemic venous circulation. The claim that hepatopetal portal blood flow is partly retained after such side-to-side procedures has been shown to be untrue if the shunts are of adequate size. ${ }^{201}, 208,216-224$ Thus, the complications of hepatic failure, including encephalopathy, after the various sideto-side shunts in controlled series have been as common as after end-to-side portacaval shunts. ${ }^{191,221,225}$ The mesocaval H-graft operation of Drapanas ${ }^{226}$ is no exception, and in addition, the prosthesis used in this procedure has had an exorbitant rate of late thrombosis. 227

\section{Selective Portal-Systemic Shunts}

The direct and indirect messages of this monograph have concerned the special qualities of portal venous blood in the maintenance of liver health. Extrahepatic diversion of this blood with a portal-systemic anastomosis imposes such a drastic handicap on the liver that this kind of procedure should be used rarely and only for overwhelming reasons. Furthermore, total portal diversion is a desirable feature of a shunting procedure only if the objective is the "metabolic engineering" described in an earlier section.

If the objective is to prevent recurrent hemorrhage from esophageal varices in a patient who still has significant hepatopetal portal venous flow, the decision to construct a selective portal-systemic shunt should be beyond rational criticism. The selective diversion procedures that have been used clinically include the original Warren-Zeppa-Fomon distal splenorenal shunt (see Fig 16,C, left side); an uncommonly performed modification also described by Warren et al., ${ }^{212}$ whereby the distal splenic vein is anastomosed to the inferior vena cava (see Fig 16,C, middle); and the direct anastomosis of the coronary vein (left gastric) to the inferior vena cava, described by Inokuchi et al. ${ }^{228}$ (see Fig 16,C, right side).

The problems with using selective shunts in patients with residual hepatopetal flow have been practical rather than conceptual. Experience with the Warren shunt has shown this shunt to be technically more sophisticated and difficult to construct than the conventional portacaval shunt. It cannot be easily constructed under the urgent circumstances of acute variceal hemorrhage, it is probably contraindicated in the presence of severe ascites, and it requires anatomically specific conditions that should be defined with preoperative angiography. ${ }^{212}$ Yet if it can be accomplished, the Warren procedure effectively decompresses esophageal varices while maintaining portal venous flow. As would be predicted, it is associated with a demonstrably better preservation of hepatic biosynthetic processes, such as urea production, ${ }^{229}$ than is portacaval shunt and it carries a far lower incidence of hepatic encephalopathy. ${ }^{200,215,222-224,230,231}$ The stakes are so high for patients who meet the candidacy criteria for a distal splenorenal shunt that it is difficult to justify consigning them by random lot to a conventional totally diverting shunt group for the purposes of a clinical study. The probability that the selective shunts are superior is not a null hypothesis. 
Nevertheless, randomized trials comparing distal splenorenal versus totally diverting shunts have not revealed a striking divergence in the life survival curves. ${ }^{200,222-224,230,231}$ If this trend continues, a better quality of life (as opposed to mere survival) may prove to be the only justification for the selective shunts.

If selective shunt procedures fail to provide a better life survival than totally diverting portacaval shunts, the most fundamental reason undoubtedly will be that the patients under treatment have progressive hepatic diseases of such an immutable course that the effect of therapeutic intervention cannot be measured accurately against the background "noise" (roar might be a better word) of the disease itself. However, other factors might play a minor role in masking the superiority of selective shunts, including a higher perioperative mortality while surgeons learn how to carry out the Warren procedure.

Finally, in most patients, the preserved residual hepatopetal portal flow is gradually "stolen" from the liver as blood from the high-pressure mesenteric bed is recruited into the lowpressure area drained by the distal splenorenal shunt. $222,232-234$ As demonstrated by Maillard et al., ${ }^{232}$ the distal splenorenal shunt carries a high flow that is driven by the splenic arterial input. Undoubtedly this protects the splenorenal anastomosis from thrombosis, but it also gives the selective shunt circuit some of the features of a thirsty and larcenous arteriovenous fistula. However, the consequent loss of portal hepatic perfusion is so gradual after distal splenorenal shunt ${ }^{222,235}$ that there is time (months or years) for compensatory physiologic adjustments, including augmentation of the hepatic arterial input. If a high intestinal venous pressure is maintained throughout this time, the absorption of ammonia and other so-called cerebral toxins should be lower than after completely diverting portacaval shunt (see earlier discussion). ${ }^{215,235}$

\section{The Concept of Portal Arterialization}

The possibility of replacing the lost portal flow with arterial blood, after a completely diverting portacaval anastomosis, has been examined in many experimental laboratories. Clinical trials with such procedures have been under way in one American center ${ }^{236}$ and one European center. ${ }^{237}$ Theoretically, such operations could have a minor beneficial effect. The hepatotrophic constituents that are diverted around the liver become available in diluted form via the arterial system and would be brought to the liver in direct relation to the quantity of hepatic flow. As discussed earlier, this is the explanation for the benefits of both the Child portacaval transposition and the portal arterialization procedures.

Nevertheless, it is important to emphasize the limitations of any benefit from such flow augmentation procedures. Marchioro et al. ${ }^{39}$ showed that the atrophic changes in liver segments deprived of splanchnic venous inflow could not be prevented by arterializing the liver tissue, even though the arterialization procedures increased the flow to several times normal. Consistent with these observations were those of Pector et al., ${ }^{80,81}$ who showed that the depressed activity of the mixed-function oxidase system could not be restored after portacaval shunt by portacaval transposition or by rearterialization of the portal vein stump.

Portal vein arterialization in experimental animals has had a specific risk. Cohn and Herrod $^{238}$ reported venous sclerosis as a consequence of the high pressure and flow. Efforts to prevent overperfusion by using very small inflow vessels or by damping flow with deliberate stenosis predictably increase the risk of thrombosis.

It is our opinion that portal arterialization procedures will have no effect whatever on either the morbidity or mortality after a completely diverting portal-systemic diversion in patients with portal hypertension. 


\section{SUMMARY}

In all species so far studied, including man, portacaval shunt causes the same changes in liver morphology, including hepatocyte atrophy, fatty infiltration, deglycogenation, depletion and disorganization of the rough endoplasmic reticulum (RER) and its lining polyribosomes, and variable but less specific damage to other organelles. Many, perhaps all, biosynthetic processes are quickly depressed, largely secondary to the selective damage to the RER, which is the "factory" of the cell.

These structural and metabolic changes in the liver after portal diversion are caused by the diversion around the liver of the hepatotrophic substances in portal venous blood, of which endogenous insulin is the most important. In experimental animals, the injury of Eck's fistula can be prevented by infusing insulin into the tied-off hilar portal vein.

The subtle but far-reaching changes in hepatic function after portal diversion have made it possible to use this procedure in palliating three inborn errors of metabolism: glycogen storage disease, familial hypercholesterolemia, and $\alpha_{1}$-antitrypsin deficiency. In these three diseases, the abnormalities caused by portal diversion have counteracted abnormalities in the patients that were caused by the inborn errors. In these diseases, amelioration of the inborn errors depends on the completeness of the portal diversion.

In contrast, total portal diversion to treat complications of portal hypertension is undesirable and always will degrade hepatic function if a significant amount of hepatopetal portal venous blood is taken from the liver. When total portal diversion is achieved (and this is to be expected after all conventional shunts), the incidence of hepatic failure and hepatic encephalopathy is increased. If portal diversion must be done for the control of variceal hemorrhage, a selective procedure such as the Warren procedure is theoretically superior to the completely diverting shunt. In practice, better patient survival has not been achieved after selective shunts than after conventional shunts, but the incidence of hepatic encephalopathy has been less.

\section{Acknowledgments}

Research was supported by grants from the Veterans Administration, by NIH project grant No. AM 29961, and by grant No. RR 00084 from the General Clinical Research Centers Program of the Division of Research Resources, NIH, Bethesda, Md.

\section{Biographies}

Thomas E. Starzl is a Professor of Surgery at the University of Pittsburgh School of Medicine. His clinical practice is at the Presbyterian University Hospital, The Children's Hospital of Pittsburgh, and the Oakland Veterans Administration Hospital. His interest in the specific effects of portal venous blood dates back to 1956. The way in which research in this field has interrelated with liver transplantation, another of his interests, has been described in this monograph. Much of the progress that was made in understanding "hepatotrophic" physiology was made possible by Dr. Starzl's longstanding collaborations with the two European co-authors of this article. 


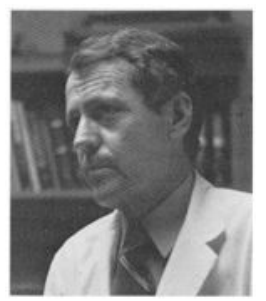

Kendrick A. Porter is Chairman of the Department of Pathology, The St. Mary's Hospital and Medical School, London. In September, 1963, Ken Porter and Tom Starzl (then at The University of Colorado) met at a meeting about renal transplantation, held at the National Science Foundation in Washington, D.C. The results being obtained with this procedure in Colorado were so striking that Dr. Porter returned to Denver with Dr. Starzl to review what was going on there. From that visit came a collaboration that has lasted for more than two decades. Dr. Porter's chapters in Dr. Starzl's books on renal (1964) and hepatic (1969) transplantation were monographs in their own right. Dr. Porter's talents soon turned to an assessment in various experimental models of the effect upon liver morphology of portal venous as opposed to systemic blood. The histopathologic changes became the most important end points in many of the complex experiments that were used to examine the hepatotrophic hypothesis. As befits an Englishman, Dr. Porter's principal side interest is gardening.

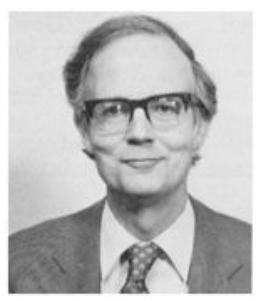

Francavilla is Professor of Biological Chemistry and Chairman of the Department of Gastroenterology at the University of Bari, Italy. His principal work in the field of portal physiology began in 1971 during a fellowship at the University of Colorado. By using biochemical techniques which identified the metabolic footprints of hormone actions, he added a new dimension to research on the specificity of portal venous blood. The way in which Dr. Francavilla's biochemical studies supported and extended the histopathologic observations of Dr. Porter was a classic demonstration of the power of interdisciplinary research. Dr. Francavilla's work in this field has continued to the present time and is currently concerned with the biochemical events and control of hepatic regeneration. Dr. Francavilla's hobbies include soccer and the production of Puglia (regional Bari) wines.

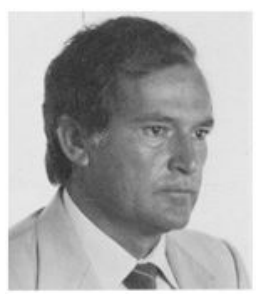




\section{References}

1. Starzl, TE.; Porter, KA.; Francavilla, A., et al. 100 years of the hepatotrophic controversy. In: Porter, R.; Whelan, J., editors. Hepatotrophic Factors; Ciba Foundation Symposium No. 55; Amsterdam: Excerpta Medica (Elsevier North-Holland); 1978. p. 111-129.

2. Starzl TE, Terblanche J. Hepatotrophic substances. Prog Liver Dis. 1979; 6:135-152. [PubMed: 396553]

3. Eck, NV. Voen Med J. Vol. 130. 1877. K voprosu o perevyazkie vorotnois veni: Predvaritelnoye soobschjenye; p. 1-2.(Ligature of the portal vein, trans. Child C.G. III: Surg. Gynecol. Obstet. 96:375-376, 1953.)

4. Warren WD. Presidential address: Reflections on the early development of portacaval shunts. Ann Surg. 1980; 191:519-527. [PubMed: 6989329]

5. Hahn M, Massen O, Nencki M, Pawlow J. Die Eck'sche Fistel zwischen der unteren Hohlvene und der Pfortader und ihre Folgen für den Organismus. Arch Exp Pathol Pharmakol. 1893; 32:161-210.

6. Carrel A, Guthrie CC. Methode simple pour etablir une fistule d'Eck. Compt Rend Soc Biol (Paris). 1906; 60:1104-1106.

7. Whipple GH, Sperry JA. Chloroform poisoning, liver necrosis, and repair. Bull Johns Hopkins Hosp. 1909; 20:278-289.

8. Bollman JL, Flock EV, Grindlay JH, et al. Coma with increased amino acids of brain and cerebrospinal fluid in dogs with Eck's fistula: Prevention by portal-systemic collateral circulation. Arch Surg. 1957; 75:405-412.

9. Bollman JL. The animal with an Eck fistula. Physiol Rev. 1961; 41:607-621.

10. Starzl TE, Porter KA, Putnam CW. Intraportal insulin protects from the liver injury of portacaval shunt in dogs. Lancet. 1975; 2:1241-1242. [PubMed: 53727]

11. Starzl TE, Porter KA, Watanabe K, et al. The effects of insulin, glucagon and insulin/glucagon infusions upon liver morphology and cell division after complete portacaval shunt in dogs. Lancet. 1976; 1:821-825. [PubMed: 56646]

12. Fisher ER, Fisher B. Ultrastructural hepatic changes following partial hepatectomy and portacaval shunt in the rat. Lab Invest. 1963; 12:929-942. [PubMed: 14063413]

13. Oudea P, Bismuth H. L'Anastomose porto-cave experimentale chez le rat normal. Pathol Biol Paris. 1965; 13:288-296. [PubMed: 14339153]

14. Rubin E, Gevirtz NR, Cohan P, et al. Liver cell damage produced by portacaval shunt. Proc Soc Exp Biol Med. 1965; 118:235-237. [PubMed: 14254556]

15. Wessel W, Cerny J, Segschneider I, et al. Electronenmikroskopische, morphometrische und histologische Untersuchungen an Rattenlebern nach Unterbindung eines Astes der Vena Portae. Beitr Pathol. 1972; 145:119-148. [PubMed: 5029851]

16. Mallet-Guy Y, Hezez G, Feroldi J. Anastomose portocave laterolaterale experimentale: Documents histologiques et electro-microscopiques. Lyon Chir. 1972; 68:436-445. [PubMed: 4659829]

17. Starzl TE, Lee I-Y, Porter KA, et al. The influence of portal blood upon lipid metabolism in normal and diabetic dogs and baboons. Surg Gynecol Obstet. 1975; 140:381-396. [PubMed: 18689027]

18. Putnam CW, Porter KA, Starzl TE. Hepatic encephalopathy and light and electron micrographic changes of the baboon liver after portal diversion. Ann Surg. 1976; 184:155-161. [PubMed: 821406]

19. Starzl TE, Putnam CW, Porter KA, et al. Portal diversion for the treatment of glycogen storage disease in humans. Ann Surg. 1973; 178:525-539. [PubMed: 4517839]

20. Starzl TE, Chase HP, Putnam CW, et al. Portacaval shunt in hyperlipoproteinaemia. Lancet. 1973; 2:940-944. [PubMed: 4126562]

21. Rous P, Larimore LD. Relation of the portal blood to liver maintenance: A demonstration of liver atrophy conditional on compensation. J Exp Med. 1920; 31:609-632. [PubMed: 19868417]

22. Mann FC. The portal circulation and restoration of the liver after partial removal. Surgery. 1940; $8: 225-238$. 
23. Mann FC. The William Henry Welch Lectures: II. Restoration and pathologic reactions of the liver. J Mt Sinai Hosp. 1944; 11:65-74.

24. Child CG, Barr D, Holswade GR, et al. Liver regeneration following portacaval transposition in dogs. Ann Surg. 1953; 138:600-608. [PubMed: 13092790]

25. Fisher B, Russ C, Updegraff H, et al. Effect of increased hepatic blood flow upon liver regeneration. Arch Surg. 1954; 69:263-272.

26. Fisher B, Fisher ER, Lee S. Experimental evaluation of liver atrophy and portacaval shunt. Surg Gynecol Obstet. 1967; 125:1253-1258. [PubMed: 6065262]

27. Sexton AW, Marchioro TL, Waddell WR, et al. Liver deglycogenation after portacaval transposition. Surg Forum. 1964; 15:120-122. [PubMed: 14189279]

28. Starzl TE, Marchioro TL, Sexton AW, et al. The effect of portacaval transposition upon carbohydrate metabolism: Experimental and clinical observations. Surgery. 1965; 57:687-697. [PubMed: 14295780]

29. Starzl, TE. (with Putnam C.W.). Experience in Hepatic Transplantation. Philadelphia, W.B: Saunders Co; 1969. p. 475-527.

30. Starzl TE, Marchioro TL, Rowlands DT Jr, et al. Immunosuppression after experimental and clinical homotransplantation of the liver. Ann Surg. 1964; 160:411-439. [PubMed: 14206848]

31. Welch CS. A note on transplantation of the whole liver in dogs. Transplant Bull. 1955; 2:54-55.

32. Marchioro TL, Porter KA, Dickinson TC, et al. Physiologic requirements for auxiliary liver homotransplantation. Surg Gynecol Obstet. 1965; 121:17-31. [PubMed: 14314095]

33. Thomford NR, Shorter RG, Hallenbeck GA. Homotransplantation of the canine liver. Arch Surg. 1965; 90:527-538. [PubMed: 14267653]

34. Halgrimson CG, Marchioro TL, Faris TD, et al. Auxiliary liver homotransplantation: Effect of host portacaval shunt. Arch Surg. 1966; 93:107-118. [PubMed: 5327725]

35. Tretbar LL, Beven EG, Hermann RE. The effects of portacaval shunt and portal flow occlusion on canine auxiliary liver homotransplants. Surgery. 1967; 61:733-738. [PubMed: 5337422]

36. Sigel B, Dunn MR, Butterfield J. Effects of partial hepatectomy and Eck fistula on autotransplanted liver tissue. Surg Forum. 1963; 14:72-74. [PubMed: 14064594]

37. Sigel B, Baldia L, Dunn MR. Studies of liver lobes autotransplanted outside the abdominal cavity. Surg Gynecol Obstet. 1967; 124:525-530. [PubMed: 5335096]

38. Marchioro TL, Porter KA, Brown BI, et al. The specific influence of non-hepatic splanchnic venous blood flow on the liver. Surg Forum. 1965; 16:280-282. [PubMed: 5835158]

39. Marchioro TL, Porter KA, Brown BI, et al. The effect of partial portacaval transposition on the canine liver. Surgery. 1967; 61:723-732. [PubMed: 4290396]

40. Price JB Jr, Voorhees AB Jr, Britton RC. The role of portal blood in regeneration and function of completely revascularized partial hepatic autografts. Surgery. 1967; 62:195-203.

41. Lee S, Keiter JE, Rosen H, et al. Influence of blood supply on regeneration of liver transplants. Surg Forum. 1969; 20:369-371. [PubMed: 4910611]

42. Chandler JG, Lee S, Krubel R, et al. The roles of inter-liver competition and portal blood in regeneration of auxiliary liver transplants. Surg Forum. 1971; 22:341-343. [PubMed: 4941322]

43. Blalock A, Mason MF. Observations on the blood flow and gaseous metabolism of the liver in unanesthetized dogs. Am J Physiol. 1936; 117:328-334.

44. Herrmann TJ, Taylor PD, Marchioro TL, et al. Oxygen and $\mathrm{C}_{2}$ content in the splanchnic and nonsplanchnic blood of dogs with portacaval transposition. Surgery. 1966; 60:1229-1231. [PubMed: 5926542]

45. Starzl TE, Francavilla A, Halgrimson CG, et al. The origin, hormonal nature, and action of hepatotrophic substances in portal venous blood. Surg Gynecol Obstet. 1973; 137:179-199. [PubMed: 4353133]

46. Pouyet M, Berard Ph, Ruckebusch Y, et al. Derivations portohepatiques selectives origine pancreatique du facteur hepatotrophique portal. Ann Chir. 1969; 23:393-402. [PubMed: 5376381]

47. Starzl TE, Porter KA, Kashiwagi N, et al. The effect of diabetes mellitus on portal blood hepatotrophic factors in dogs. Surg Gynecol Obstet. 1975; 140:549-562. [PubMed: 18689029] 
48. Starzl TE, Porter KA, Kashiwagi N, et al. Portal hepatotrophic factors, diabetes mellitus and acute liver atrophy, hyertrophy and regeneration. Surg Gynecol Obstet. 1975; 141:843-858. [PubMed: 1188560]

49. Izzo JL, Bartlett JW, Roncone A, et al. Physiological processes and dynamics in the disposition of small and large doses of biologically active and inactive ${ }^{131}$ I-insulins in the rat. J Biol Chem. 1967; 242:2343-2355. [PubMed: 6026231]

50. Blackard WG, Nelson NC. Portal and peripheral vein immunoreactive insulin concentrations before and after glucose infusion. Diabetes. 1970; 19:302-306. [PubMed: 5443433]

51. Field JB. Extraction of insulin by liver. Annu Rev Med. 1973; 24:309-314. [PubMed: 4575861]

52. Starzl TE, Francavilla A, Porter KA, et al. The effect upon the liver of evisceration with or without hormone replacement. Surg Gynecol Obstet. 1978; 146:524-531. [PubMed: 205003]

53. Starzl TE, Francavilla A, Porter KA, et al. The effect of splanchnic viscera removal upon canine liver regeneration. Surg Gynecol Obstet. 1978; 147:193-207. [PubMed: 210529]

54. Reaven EP, Peterson DT, Reaven GM. The effect of experimental diabetes mellitus and insulin replacement on hepatic ultrastructure and protein synthesis. J Clin Invest. 1973; 52:248-262. [PubMed: 4683872]

55. Gerschenson LE, Okigaki T, Andersson M, et al. Fine structural and growth characteristics of cultured rat liver cells: Insulin effects. Exp Cell Res. 1972; 71:49-58. [PubMed: 4554574]

56. Wagle SR, Ingebretsen WR Jr, Sampson L. Studies on the effects of insulin on glycogen synthesis and ultrastructure in isolated rat liver hepatocytes. Biochem Biophys Res Commun. 1973; 53:937943. [PubMed: 4354454]

57. Junge U, Nagamori S. Effect of insulin and glucagon on the DNA synthesis of hepatocyte cultures. Verh Dtsch Ges Inn Med. 1976; 82:385-386. [PubMed: 1029217]

58. Bernaert D, Wanson J-C, Drochmans P, et al. Effect of insulin on ultrastructure and glycogenesis in primary cultures of adult rat hepatocytes. J Cell Biol. 1977; 74:878-900. [PubMed: 409722]

59. Ozawa K, Yamada T, Honjo I. Role of insulin as a portal factor in maintaining the viability of liver. Ann Surg. 1974; 180:716-719. [PubMed: 4417210]

60. Ozawa K, Yamaoka Y, Nanbu J, et al. Insulin as the primary factor governing changes in mitochondrial metabolism leading to liver regeneration and atrophy. Am J Surg. 1974; 127:669_ 675. [PubMed: 4832136]

61. Silen W, Mawdsley DL, Weirich WL, et al. Studies of hepatic function in dogs with Eck fistula or portacaval transposition. Arch Surg. 1957; 74:964-973.

62. Owsley JQ, Goin JM, Clarke JC, et al. A comparison of galactose clearance by the liver following portacaval transposition or Eck fistula. Surg Forum. 1958; 9:515-518. [PubMed: 13635436]

63. Fawcett, DW. The Cell. Philadelphia, W.B: Saunders Co; 1981. p. 303-309.

64. Jones AL, Ruderman NB, Herrera MG. An electron microscopic study of lipoprotein production and release by the isolated perfused rat liver. Proc Soc Exp Biol Med. 1966; 123:4-9. [PubMed: 5924455]

65. Winter IC, van Dolah HD, Crandell LA. Lowered serum lipid levels in the Eck fistula dog. Am J Physiol. 1941; 133:566-571.

66. Starzl, TE.; Putnam, CW.; Porter, KA., et al. Portacaval shunt for glycogen storage disease and hyperlipidaemia. In: Porter, R.; Whelan, J., editors. Hepatotrophic Factors; Ciba Foundation Symposium No. 55; Amsterdam: Excerpta Medica (Elsevier North-Holland); 1978. p. 311-330.

67. James JH, Soeters PB, Escourrou J, et al. Decreased cholesterol and fatty acid synthesis following portacaval shunt. Surg Forum. 1977; 28:397-399. [PubMed: 617481]

68. Proia A, McNamara DJ, Edwards KDG, et al. Cholesterol homeostasis in the rat with a portacaval anastomosis. Proc Natl Acad Sci USA. 1979; 76:4654-4657. [PubMed: 291994]

69. Pector JC, Winand J, DeHaye JP, et al. Effects of portacaval shunt and transposition on fatty acid and cholesterol biosynthesis in rat liver. Am J Physiol. 1980; 239:G83-89. [PubMed: 6157328]

70. Francavilla A, Jones AF, Benichou J, et al. The effect of portacaval shunt upon hepatic cholesterol synthesis and cyclic AMP in dogs and baboons. J Surg Res. 1980; 28:1-7. [PubMed: 6244463]

71. Chase HP, Morris T. Cholesterol metabolism following portacaval shunt in the pig. Atherosclerosis. 1976; 24:141-148. [PubMed: 182182] 
72. Carew TE, Saik RP, Johansen KH, et al. Low density and high density lipoprotein turnover following portacaval shunt in swine. J Lipid Res. 1976; 17:441-450. [PubMed: 184221]

73. Nestruck AC, Bergseth M, Bidallier M, et al. Lipid and lipoprotein secretion following portacaval shunt in swine. Atherosclerosis. 1978; 29:355-362. [PubMed: 208587]

74. Bilheimer DW, Goldstein JL, Grundy SM, et al. Reduction in cholesterol and low density lipoprotein synthesis after portacaval shunt surgery in a patient with homozygous familial hypercholesterolemia. J Clin Invest. 1975; 56:1420-1430. [PubMed: 172531]

75. McNamara DJ, Ahrens EH Jr, Kolb R, et al. Treatment of familial hypercholesterolemia by portacaval anastomosis: Effect on cholesterol metabolism and pool sizes. Circulation. 1982; 66:II159.

76. Kuo J, Pertsemlidis D, Panveliwalla D. Effects of portacaval shunt on bile acid metabolism in dogs. Surg Forum. 1977; 28:402-403. [PubMed: 364729]

77. Reichle FA, Bernstein MR, Hower RD, et al. Urea cycle enzyme activity in human hepatic cirrhosis and after experimental portacaval shunt. Surg Forum. 1973; 24:246-248. [PubMed: 4805998]

78. Reichle FA, Rao NS, Reichle RM, et al. The mechanism of postshunt liver failure. Surgery. 1977; 82:738-749. [PubMed: 918862]

79. Rubin E, Hutterer F, Ohshiro T, et al. Effect of experimental portacaval shunt on hepatic drug metabolizing enzymes. Proc Soc Exp Biol Med. 1968; 127:444-447. [PubMed: 5645032]

80. Pector JC, Verbeustel S, Lambilliotte JP. Effect of portal arterialization on hepatic cytochrome P-450 in rats with portacaval shunt. Digestion. 1975; 12:144-151. [PubMed: 1183748]

81. Pector JC, Ossenberg FW, Peignoux M, et al. The effect of portacaval transposition on hepatic cytochrome P-450 in the rat. Biomedicine. 1975; 23:160-162. [PubMed: 1191728]

82. Ossenberg FW, Pointard L, Benhamou JP. Effect of portacaval shunt on hepatic cytochrome P-450 in rats. Rev Eur Etudes Clin Biol. 1972; 17:791-793.

83. Vassanelli P, Chiesara E. Microsomal drug-metabolizing enzymes activity and induction in the rat liver after portacaval shunt. Arch Int Pharmacodyn Ther. 1972; 196(suppl):158-161. [PubMed: 5052474]

84. Lauterberg BH, Bircher J. Expiratory measurement of maximum aminopyrine demethylation in vivo: Effect of phenobarbital, partial hepatectomy, portacaval shunt and bile duct ligation in the rat. J Pharmacol Exp Ther. 1976; 196:501-509. [PubMed: 1255494]

85. Hirokata Y, Tong S, Siddik ZH, et al. Sex-dependent differences in the effects of portacaval anastomosis on hepatic monooxygenases in rats. Biochem Pharmacol. 1982; 31:499-502. [PubMed: 6802138]

86. Proia AD, Edwards KDG, McNamara DJ, et al. Nutritional influences on the hepatic mixedfunction oxidase system in the rat with a portacaval anastomosis. Gastroenterology. to be published.

87. Kato R. Drug metabolism under pathological and abnormal physiological states in animals and man. Xenobiotica. 1977; 7:25-92. [PubMed: 322397]

88. Battisto JR, Miller J. Immunologic unresponsiveness produced in adult guinea pigs by parenteral introduction of minute quantities of hapten or protein antigen. Pro Soc Exp Biol Med. 1962; 111:111-115.

89. Cantor HM, Dumont AE. Hepatic suppression of sensitization to antigen absorbed into the portal system. Nature. 1967; 215:744-745. [PubMed: 6059543]

90. Chase MW. Inhibition of experimental drug allergy by prior feeding of the sensitizing agent. Proc Soc Exp Biol Med. 1946; 61:257-259. [PubMed: 21024163]

91. Franzl RE. Immunogenic sub-cellular particles obtained from spleens of antigen-injected mice. Nature. 1962; 195:457-458. [PubMed: 13894735]

92. Mandel MA, Monaco AP, Russell PS. Destruction of splenic transplantation antigens by a factor present in liver. J Immunol. 1965; 95:673-682. [PubMed: 4953954]

93. Paronetto F, Popper H. Enhanced antibody formation in experimental acute and chronic liver injury produced by carbon tetrachloride or allyl alcohol. Proc Soc Exp Biol Med. 1964; 116:10601064. [PubMed: 14230344] 
94. Triger DR, Cynamon MH, Wright R. Studies on hepatic uptake of antigen: I. Comparison of inferior vena cava and portal vein routes of immunization. Immunology. 1973; 25:941-950. [PubMed: 4759563]

95. Triger DR, Wright R. Hyperglobulinaemia in liver disease. Lancet. 1973; 1:1494-1496. [PubMed: 4123153]

96. Edelstone DI, Yonemoto RH, Hargreaves R. The liver as a lymphocyte antigen modifier. Surg Forum. 1971; 22:280-282. [PubMed: 4941314]

97. Lisboa LS, Holyoke ED. Determination of mechanism of enhancement of tumor take by transhepatic passage of antigen. Surg Forum. 1972; 23:116-118. [PubMed: 4671045]

98. Mayer DJ, Kronman B, Dumont AE. Enhancement of skin homografts by active immunization. Surg Forum. 1965; 16:243-245. [PubMed: 5319669]

99. Barker CF, Corriere JN Jr. Canine renal homotransplantation with venous drainage via the portal vein. Ann Surg. 1967; 165:279-282. [PubMed: 5334572]

100. Fukuda A, Hanaoko T, Soloway AC, et al. Inhibition of second-set renal allograft responses by portal vein drainage. Transplant Proc. 1969; 1:602-604. [PubMed: 4944277]

101. Hickman R, Terblanche J. Portal venous drainage of renal transplants in pigs. Transplantation. 1975; 20:338-340. [PubMed: 1099738]

102. May AG, Bauer S, Leddy JP, et al. Survival of allografts after hepatic portal venous administration of specific transplantation antigen. Ann Surg. 1969; 170:824-832. [PubMed: 4899836]

103. Mazzoni G, DiMartino C, Demofonti A, et al. A comparison of portal and systemic venous drainage in porcine renal allografts. Br J Surg. 1972; 59:541-544. [PubMed: 4557358]

104. Mazzoni G, DiMartino C, Melis M, et al. Organ transplantation in pigs with different portal and caval venous drainage. Eur Surg Res. 1971; 3:62-71. [PubMed: 4939503]

105. Sakai A. Role of the liver in kidney allograft rejection in the rat. Transplantation. 1970; 9:333334.

106. Boeckx W, Sobis H, Lacquet A, et al. Prolongation of allogenic heart graft survival in the rat after implantation on portal vein. Transplantation. 1975; 19:145-149. [PubMed: 1091038]

107. Eloy R, Kedinger M, Garaud K, et al. Isogenic and allogenic transplantation of isolated langerhans islets into the liver. Langenbecks Arch Chir. 1975; 109(suppl):109-114. [PubMed: 813071]

108. Ziegler MM, Reckard CR, Barker CF. Extended function of isolated pancreatic islet isografts and allografts. Transplant Proc. 1975; 7:743-745.

109. Pfefferman R, Sakai A, Kountz SL. The liver as a privileged site for parathyroid alloimplantation in the rat. Surgery. 1976; 79:182-187. [PubMed: 1082177]

110. Mazzoni G, Benichou J, Porter KA, et al. Renal homotransplantation with venous outflow or infusion of antigen into the portal vein of dogs or pigs. Transplantation. 1977; 24:268-273. [PubMed: 335585]

111. McDermott WV Jr, Adams RD. Episodic stupor associated with an Eck fistula in the human with particular reference to the metabolism of ammonia. J Clin Invest. 1954; 33:1-8. [PubMed: 13117957]

112. McDermott WV Jr, Adams RD, Riddell AG. Ammonia metabolism in man. Ann Surg. 1954; 140:539-556. [PubMed: 13198089]

113. Hubbard TB Jr. Carcinoma of the head of the pancreas: Resection of the portal vein and portacaval shunt. Ann Surg. 1958; 147:935-944. [PubMed: 13534264]

114. Henzel J, Turcotte JG, Child CG III. The response of normal rats to portacaval shunt. Arch Surg. $1963 ; 86: 342-348$.

115. Lee SH, Fisher B. Portacaval shunt in the rat. Surgery. 1961; 50:668-672. [PubMed: 14463560]

116. Assal J-P, Levrat R, Cahn T, et al. Metabolic consequences of portacaval shunting in the rat: Effects on weight, food intake, intestinal absorption, and hepatic morphology. Z Gesamte Exp Med. 1971; 154:87-97. [PubMed: 5102385]

117. Kyu MH, Cavanagh JB. Some effects of portacaval anatomosis in the male rat. Br J Exp Pathol. 1970; 51:217-227. [PubMed: 5420993] 
118. Cuschiera A, Baker PR, Holley MP, et al. Portacaval shunt in the pig: I. Effect upon survival, behavior, nutrition, and liver function. J Surg Res. 1974; 17:387-396. [PubMed: 4155012]

119. Hickman R, Corsier JH, Saunders SJ, et al. Transhepatic metabolism after end-to-side portacaval shunt in the young pig. Surgery. 1974; 76:601-607. [PubMed: 4416696]

120. Detrie, Ph. Treatment of ammonia intoxication in the rhesus monkey by total colectomy. J Chir (Paris). 1965; 90:491-494.

121. Zuidema GD, Fletcher M, Burton WD, et al. Blood ammonia studies in monkeys before and after portacaval anastomosis. Arch Surg. 1962; 85:152-157.

122. Kline DG, Crook JN, Nance FC. Eck fistula encephalopathy: Long-term studies in primates. Ann Surg. 1971; 173:97-101. [PubMed: 5543554]

123. Malatack JJ, Finegold DN, Iwatsuki S, et al. Liver transplantation for type I glycogen storage disease. Lancet. 1983; 1:1073-1076. [PubMed: 6133106]

124. Starzl TE, Chase HP, Ahrens EH Jr, et al. Portacaval shunt in patients with familial hypercholesterolemia. Ann Surg. September.1983 :192. [PubMed: 6870377]

125. Warren WD, Millikan WJ Jr, Smith RB III, et al. Noncirrhotic portal vein thrombosis: Physiology before and after shunts. Ann Surg. 1980; 192:341-349. [PubMed: 7416830]

126. Grauer SE, Schwartz SI. Extrahepatic portal hypertension: A retrospective analysis. Ann Surg. 1979; 189:566-574. [PubMed: 312627]

127. Fonkalsrud EW, Myers NA, Robinson MJ. Management of extrahepatic portal hypertension in children. Ann Surg. 1974; 180:487-493. [PubMed: 4472192]

128. Lambert MJ III, Tank ES, Turcotte JG. Late sequelae of mesocaval shunts in children. Am J Surg. 1974; 127:19-24. [PubMed: 4543448]

129. Alvarez F, Bernard O, Brunelle F, et al. Portal obstruction in children: II. Results of surgical portosystemic shunts. J Pediatr. November.1983 103:703-707. [PubMed: 6605420]

130. Mikkelsen WP, Edmondson HA, Peters RL, et al. Extra- and intrahepatic portal hypertension without cirrhosis (hepatoportal sclerosis). Ann Surg. 1965; 162:602-620. [PubMed: 5833586]

131. Voorhees AB Jr, Chaitman E, Schneider S, et al. Portal-systemic encephalopathy in the noncirrhotic patient. Arch Surg. 1973; 107:659-663. [PubMed: 4744282]

132. Child, CG., III; Turcotte, JG. Surgery and portal hypertension. In: Child, CG., editor. The Liver and Portal Hypertension. Philadelphia: W.B. Saunders Co; 1964. p. 49-55.

133. Reynolds TB. Promises! Promises! Hemodynamics and portal-systemic shunt. N Engl J Med. 1974; 290:1484-1485. [PubMed: 4275484]

134. Burchell AR, Moreno AH, Panke WF, et al. Hemodynamic variables and prognosis following portacaval shunts. Surg Gynecol Obstet. 1974; 138:359-369. [PubMed: 4811321]

135. Riddell AG, Davies RP, Clark AD. Portacaval transposition in the treatment of glycogen storge disease. Lancet. 1966; 2:1146-1148. [PubMed: 4162539]

136. Liebschutz D, Soper RT. Portacaval shunt in siblings for type I glycogenosis. J Pediatr Surg. 1976; 11:557-561. [PubMed: 823318]

137. Corbeel L, Hue L, Lederer B, et al. Clinical and biochemical findings before and after portacaval shunt in a girl with type Ib glycogen storage disease. Pediatr Res. 1981; 15:58-61. [PubMed: 6259580]

138. Folkman J, Philippart A, Tze W-J, et al. Portacaval shunt for glycogen storage disease: Value of prolonged intravenous hyperalimentation before surgery. Surgery. 1972; 72:306-314. [PubMed: 4626293]

139. Greene HL, Slonim AE, O’Neill JA, et al. Continuous nocturnal intragastric feedings for management of type I glycogen storage disease. N Engl J Med. 1976; 294:1125-1129.

140. Crigler, JF., Jr; Folkman, J. Glycogen storage disease: New approaches to therapy. In: Porter, R.; Whelan, J., editors. Hepatotrophic Factors; Ciba Foundation Symposium No. 55; Amsterdam: Excerpta Medica (Elsevier North-Holland); 1978. p. 331-356.

141. Lockwood DH, Merimee TJ, Edgar PJ, et al. Insulin secretion in type I glycogen storage disease. Diabetes. 1969; 18:755-758. [PubMed: 5259818]

142. Starzl TE, Iwatsuki S, Van Thiel DH, et al. Evolution of liver transplantation. Hepatology. 1982; 2:614-636. [PubMed: 6749635] 
143. Levine OR, Harris RC, Blanc WA, et al. Progressive pulmonary hypertension in children with portal hypertension. J Pediatr. 1973; 83:964-972. [PubMed: 4757535]

144. Howell RR, Stevenson RE, Ben-Menachem Y, et al. Hepatic adenomata with type I glycogen storage disease. JAMA. 1976; 236:1481-1484. [PubMed: 183026]

145. Goldstein J, Brown MS. Binding and degradation of low density lipoproteins in cultured human fibroblasts: Comparison of cells from a normal subject and from a patient with homozygous familial hypercholesterolemia. J Biol Chem. 1974; 249:5153-5162. [PubMed: 4368448]

146. Goldstein JL, Dana SE, Brunschede GY, et al. Genetic heterogeneity in familial hypercholesterolemia: Evidence for two different mutations affecting functions of low density lipoprotein receptor. Proc Natl Acad Sci USA. 1975; 72:1092-1096. [PubMed: 236556]

147. Faergeman O, Gormsen J, Meinertz H. Anti-platelet drugs and portacaval anastomosis for homozygous hypercholesterolemia, letter. Lancet. 1976; 2:1416. [PubMed: 63884]

148. Clatworthy, HW, Jr. Extrahepatic portal hypertension. In: Child, CG., editor. Portal Hypertension. Philadelphia: W.B. Saunders Co; 1974. p. 257-261.

149. Forman MB, Baker SG, Mieny CJ, et al. Treatment of homozygous familial hypercholesterolemia with portacaval shunt. Atherosclerosis. 1982; 41:349-361. [PubMed: 7066082]

150. Krogh L, Wickens JT. Portacaval shunt for hypercholesterolemia. S Afr Med J. 1974; 48:2302. [PubMed: 4439106]

151. Cywes S, Davies MRQ, Louw JH, et al. Portacaval shunt in two patients with homozygous type II hyperlipoproteinemia. S Afr Med J. 1976; 50:239-242. [PubMed: 176738]

152. Farriaux JP, Ribet M, Bertrand M, et al. Treatment of type II familial hypercholesterolemia with portacaval anastomosis. Arch Fr Pediatr. 1976; 33:745-759. [PubMed: 185982]

153. Weglicki WB, Ganda OP, Soeldner JS, et al. Portacaval diversion for severe hypercholesterolemia. Arch Surg. 1977; 112:634-640. [PubMed: 857765]

154. Soutar AK, Myant NB, Thompson GR. Measurement of apolipoprotein B turnover in very low and low density lipoproteins in familial hypercholesterolemia. Atherosclerosis. 1977; 28:247256. [PubMed: 202289]

155. Blanchard H, Bensoussan AL, Collin PP, et al. Terminolateral portacaval anastomosis in type II homozygous familial hypercholesterolemia. Chir Pediatr. 1979; 20:221-226. [PubMed: 487516]

156. Miettinen, TA. Comparison of cholestyramine, ileal bypass, and portacaval shunt in the treatment of familial hypercholesterolemia. In: Gotto, AM., Jr; Smith, LC.; Allen, B., editors. Atherosclerosis: V Proceedings of the Fifth International Symposium of Atherosclerosis. New York: Springer Verlag; 1980. p. 470-473.

157. Madras PN. Portacaval shunt for familial heterozygous hypercholesterolemia. Surg Gynecol Obstet. 1981; 152:187-190. [PubMed: 7209760]

158. Starzl TE, Chase HP, Putnam CW, et al. Follow-up of patient with portacaval shunt for the treatment of hyperlipidemia. Lancet. 1974; 2:714-717. [PubMed: 4142980]

159. Shurberg JL, Resnick RH, Koff RS, et al. Serum lipids, insulin, and glucagon after portacaval shunt in cirrhosis. Gastroenterology. 1977; 72:301-304. [PubMed: 830579]

160. Stein EA, Mieny C, Spitz L, et al. Portacaval shunt in four patients with homozygous hypercholesterolemia. Lancet. 1975; 1:832-835. [PubMed: 48058]

161. Ginsberg H, Davidson N, Le N-A, et al. Marked overproduction of low density lipoprotein apoprotein-B in a subject with heterozygous familial hypercholesterolemia: Effect of portacaval shunting. Biochim Biophys Acta. 1983; 712:250-259. [PubMed: 7126604]

162. Small DM, Shipley GG. Physical-chemical basis of lipid deposition in atherosclerosis: The physical state of the lipids helps to explain lipid deposition and lesion reversal in atherosclerosis. Science. 1974; 185:222-229. [PubMed: 4833824]

163. Farriaux JP, Bertrand M, Ribet M. Hypercholesterolemia, portacaval shunt and coronary disease, letter. N Engl J Med. 1979; 301:108. [PubMed: 449935]

164. Buchwald H, Moore RB, Varco RL. Ten years clinical experience with partial ileal by-pass in management of the hyperlipidemias. Ann Surg. 1974; 180:384-392. [PubMed: 4416064]

165. Guzman IJ, Schneider PD, Coyle JJ, et al. Combined hypolipidemia of portacaval transposition and ileal resection in the dog. Surg Gynecol Obstet. 1980; 150:475-480. [PubMed: 7361231] 
166. Thompson JS, Porter KA, Hayashida N, et al. Morphologic and biochemical changes in dogs after portacaval shunt plus bile fistula or ileal bypass: Failure of bile fistula or ileal by-pass to prevent hepatocyte atrophy. Hepatology. 1983; 3:581-587. [PubMed: 6862371]

167. Rucker RD Jr, Guzman IJ, Snover D, et al. Long-term hypolipidemic effect of portacaval transposition and distal intestinal resection without change in liver function tests. J Surg Res. 1982; 32:423-428. [PubMed: 7087431]

168. Anderson JM, Nervi FO, Dietschy JM. Rate constants for the uptake of cholesterol from various intestinal regions and serum lipoprotein functions by the liver of the rat in vivo. Biochim Biophys Acta. 1977; 486:298-307. [PubMed: 836859]

169. Kovanen PT, Bilheimer DW, Goldstein JL, et al. Regulatory role for hepatic low density lipoprotein receptors in vivo in the dog. Proc Natl Acad Sci USA. 1981; 78:1194-1198. [PubMed: 6262757]

170. Van'T Hooft FM, Hardman DA, Kane JP, et al. Apolipoprotein B(B-48) of rat chylomicrons is not a precursor of the apolipoprotein of low density lipoproteins. Proc Natl Acad Sci USA. 1982; 79:179-182. [PubMed: 6948299]

171. Hoeg JM, Demosky SJ Jr, Schaefer EJ, et al. Direct measurement of binding of low density lipoproteins (LDL) to human hepatic membranes from normal patients and patients with homozygous type II hyperlipoproteinemia. Clin Res. 1982; 30:193a.

172. Starzl, TE.; Porter, KA.; Terblanche, J. Inter-organ communications; with particular reference to hepatotrophic factors and intrinsic liver growth factors. In: Popper, H.; Gudat, F.; Bianchi, L., et al., editors. Communications of Liver Cells; Proceedings of Falk Symposium No. 27; Lancaster, England: MTP Press, Ltd; 1980. p. 93-97.

173. Laurell C-B, Ericksson S. The electrophoretic alpha-1-globulin pattern of serum in patients with alpha-1-antitrypsin deficiency. Scand J Clin Lab Invest. 1963; 15:132-140.

174. Sharp HL, Bridges RA, Krivit W, et al. Cirrhosis associated with alpha-1-antitrypsin deficiency: A previously unrecognized inherited disorder. J Lab Clin Med. 1969; 73:934-939. [PubMed: 4182334]

175. Aagenaes O, Fagerhol M, Elgjo K, et al. Pathology and pathogenesis of liver disease in alpha-1antitrypsin deficient individuals. Postgrad Med J. 1974; 50:365-375. [PubMed: 4549449]

176. Talamo RC, Feingold M. Infantile cirrhosis with hereditary alpha-1-antitrypsin deficiency: Clinical improvement in two siblings. Am J Dis Child. 1973; 125:845-847. [PubMed: 4196606]

177. Hood JM, Koep LJ, Peters RL, et al. Liver transplantation for advanced liver disease with alpha-1-antitrypsin deficiency. N Engl J Med. 1980; 302:272-275. [PubMed: 6985708]

178. Lammens P, Levey VG, Martin JP, et al. Syndrome de Budd-Chiari associe a un deficit en alpha-1-antitrypsine de type PiS ou PiSO. Med Chir Dig. 1974; 3:409-415. [PubMed: 4549251]

179. Moroz SP, Cutz E, Balfe JW, et al. Membranoproliferative glomerulonephritis in childhood cirrhosis associated with alpha-1-antitrypsin deficiency. Pediatrics. 1976; 57:232-238. [PubMed: 1082572]

180. McPhie JL, Binnie S, Brunt PW. Alpha-1-antitrypsin deficiency and infantile liver disease. Arch Dis Child. 1976; 51:584-588. [PubMed: 1085610]

181. Sotos JF, Cutler EA, Romshe CA, et al. Successful splenorenal shunt and splenectomy in two patients with alpha-1-antitrypsin deficiency. J Pediatr Surg. 1981; 16:12-16. [PubMed: 6971926]

182. Starzl TE, Porter KA, Francavilla A, Iwatsuki S. Reversal of hepatic alpha-1-antitrypsin deposition after portacaval shunt. Lancet. 1983; 2:424-426. [PubMed: 6135912]

183. Donovan AJ, Covey PC. Early history of the portacaval shunt in humans. Surg Gynecol Obstet. 1978; 147:423-430. [PubMed: 356307]

184. Vidal M. Traitment chirurgical des ascites dans les cirrhoses du foie. 16th Congress Francais de Chirurgie. 1903; 16:294-304.

185. Whipple AO. The problem of portal hypertension in relation to the hepatosplenopathies. Ann Surg. 1945; 122:449-475. [PubMed: 17858664]

186. Blakemore AH, Lord JW Jr. The technique of using vitallium tubes in establishing portacaval shunts for portal hypertension. Ann Surg. 1945; 122:476-489. [PubMed: 17858665]

187. LeVeen HH, Christoudias G, Ip M. Peritoneo-venous shunting for ascites. Ann Surg. 1974; 180:580-591. [PubMed: 4415019] 
188. Resnick RH, Chalmers TC, Ishihara AM, et al. (Boston Inter-Hospital Liver Group). A controlled study of the prophylactic portacaval shunt: A final report. Ann Intern Med. 1969; 70:675-688. [PubMed: 4890511]

189. Jackson FC, Perrin EB, Smith AG, et al. A clinical investigation of the portacaval shunt: II. Survival analysis of the prophylactic operation. Am J Surg. 1968; 115:22-42. [PubMed: 5299657]

190. Conn HO, Lindenmuth WW, May CJ, et al. Prophylactic portacaval anastomosis: A tale of two studies. Medicine. 1972; 51:27-40. [PubMed: 4536676]

191. Resnick RH, Iber FL, Ishihara AM, et al. (Boston Inter-Hospital Liver Group). A controlled study of the therapeutic portacaval shunt. Gastroenterology. 1974; 67:843-857. [PubMed: 4547724]

192. Jackson FC, Perrin EB, Felix WR, et al. A clinical investigation of the portacaval shunt: V. Survival analysis of the therapeutic operation. Ann Surg. 1971; 174:672-701. [PubMed: 5098227]

193. Rueff B, Degos F, Degos J-D, et al. A controlled study of therapeutic portacaval shunt in alcoholic cirrhosis. Lancet. 1976; 1:655-659. [PubMed: 73637]

194. Reynolds TB, Donovan AJ, Mikkelsen WP, et al. Results of a 12-year randomized trial of portacaval shunt in patients with alcoholic liver disease and bleeding varices. Gastroenterology. 1981; 80:1005-1011. [PubMed: 7009309]

195. Johnston GW, Rodgers HW. A review of 15 years' experience in the use of sclerotherapy in the control of acute haemorrhage from oesophageal varices. Br J Surg. 1973; 60:797-800. [PubMed: 4542942]

196. Terblanche J, Northover JMA, Bornman P, et al. A prospective evaluation of injection sclerotherapy in the treatment of acute bleeding from esophageal varices. Surgery. 1979; 85:239245. [PubMed: 311524]

197. Lewis J, Chung RS, Allison J. Sclerotherapy of esophageal varices. Arch Surg. 1980; 115:476481. [PubMed: 6965854]

198. Lunderquist A, Vang J. Transhepatic catheterization and obliteration of the coronary vein in patients with portal hypertension and esophageal varices. N Engl J Med. 1974; 291:646-649. [PubMed: 4546968]

199. Bengmark S, Borjesson B, Hoevels J, et al. Obliteration of esophageal varices by PTP: A followup of 43 patients. Ann Surg. 1979; 190:549-554. [PubMed: 384946]

200. Conn, HO. Complications of portal hypertension. In: Gitnick, GL., editor. Current Hepatology. New York: John Wiley \& Sons; 1982. p. 131-194.

201. Rikkers LF. Operations for management of esophageal variceal hemorrhage. West J Med. 1982; 136:107-121. [PubMed: 7039135]

202. Malt RA. Portasystemic venous shunts: Parts I and II. N Engl J Med. 1976; 295:24-29. 80-86. [PubMed: 1083939]

203. Viamonte M Jr, Warren WD, Fomon JJ, et al. Angiographic investigations in portal hypertension. Surg Gynecol Obstet. 1970; 130:37-53. [PubMed: 4312013]

204. Nordlinger BM, Nordlinger DF, Fulenwider JT, et al. Angiography in portal hypertension: Clinical significance in surgery. Am J Surg. 1980; 139:132-141. [PubMed: 7350837]

205. Rousselot LM, Ruzicka FF, Doehner GA. Portal venography via the portal and percutaneous routes: Anatomic and clinical studies. Surgery. 1953; 34:557-569. [PubMed: 13090044]

206. Okuda K, Suzuki K, Musha H, et al. Percutaneous transhepatic catheterization of the portal vein for the study of portal hemodynamics and shunts: A preliminary report. Gastroenterology. 1977; 73:279-284. [PubMed: 873129]

207. Viallet A, Legare A, Lavole P. Hepatic and umbilicoportal catheterization in portal hypertension. Ann NY Acad Sci. 1970; 170:177-192.

208. Rikkers LF, Miller FJ, Christian P. Effect of portasystemic shunt operations on hepatic portal perfusion. Am J Surg. 1981; 141:169-174. [PubMed: 7457721]

209. Womack NA, Peters RM. An investigation of the relationship between portal venous pressure and inferior vena caval and portal venous oxygen saturations. Ann Surg. 1957; 146:691-699. [PubMed: 13470759] 
210. Johnson G Jr, Womack NA, Gabriele OF, et al. Control of the hyperdynamic circulation in patients with bleeding esophageal varices. Ann Surg. 1969; 169:661-671. [PubMed: 5305164]

211. Warren WD, Zeppa R, Fomon JJ. Selective transsplenic decompression of gastroesophageal varices by distal splenorenal shunt. Ann Surg. 1967; 166:437-455. [PubMed: 6068492]

212. Warren WD, Millikan WJ Jr, Henderson JM, et al. Ten years portal hypertensive surgery at Emory: Results and new perspectives. Ann Surg. 1982; 195:530-542. [PubMed: 7073351]

213. Price JB Jr, McCullough W, Peterson L, et al. Increased intestinal absorption resulting from portal systemic shunting in the dog and man. Surg Forum. 1966; 17:367-368. [PubMed: 5920965]

214. Harrison ID, Hardy-Smith A, Shields R. Ammonia absorption from the canine colon after portacaval shunt. Br J Surg. 1977; 64:851-856. [PubMed: 22373]

215. Rikkers LF. Portal hemodynamics, intestinal absorption, and post-shunt encephalopathy. Surgery. 1983; 94:126-133. [PubMed: 6879434]

216. Fulenwilder JT, Nordlinger BM, Millikan WJ, et al. Portal pseudoperfusion: An angiographic illusion. Ann Surg. 1979; 189:257-268. [PubMed: 556536]

217. Redeker AG, Kunelis CT, Yamamoto S, et al. Assessment of portal and hepatic hemodynamics after side-to-side portacaval shunt in patients with cirrhosis. J Clin Invest. 1964; 43:1464-1471. [PubMed: 14192527]

218. Warren WD, Muller WH. A clarification of some hemodynamic changes in cirrhosis and their surgical significance. Ann Surg. 1959; 150:413-427. [PubMed: 13842955]

219. Britton RC, Voorhees AB Jr, Price JB Jr. Perfusion of the liver following side-to-side portacaval shunt. Surgery. 1967; 62:181-188.

220. Mulder DG, Plested WG III, Hanafee WN, et al. Hepatic circulatory and functional alterations following side-to-side portacaval shunt. Surgery. 1966; 59:923-931. [PubMed: 5937966]

221. Bismuth H, Franco D, Hepp J. Portal-systemic shunt in hepatic cirrhosis: Does the type of shunt decisively influence the clinical result? Ann Surg. 1974; 179:209-218. [PubMed: 4544047]

222. Rikkers LF, Rudman D, Galambos JT, et al. A randomized, controlled trial of the distal splenorenal shunt. Ann Surg. 1978; 188:271-282. [PubMed: 308357]

223. Reichle FA, Fahmy WF, Golsorkhi M. Prospective comparative clinical trial with distal splenorenal and mesocaval shunt. Am J Surg. 1979; 137:13-21. [PubMed: 310249]

224. Reichle FA, Owen OE. Hemodynamic patterns in human hepatic cirrhosis: A prospective randomized study of the hemodynamic sequelae of distal splenorenal (Warren) and mesocaval shunts. Ann Surg. 1979; 190:523-534. [PubMed: 314787]

225. Malt RA, Szczerban J, Malt RB. Risks in therapeutic portacaval and splenorenal shunts. Ann Surg. 1976; 184:279-288. [PubMed: 962396]

226. Drapanas T. Interposition mesocaval shunt for treatment of portal hypertension. Ann Surg. 1972; 176:435-448. [PubMed: 4263236]

227. Smith RB III, Warren WD, Salam AA, et al. Dacron interposition shunts for portal hypertension: An analysis of morbidity correlates. Ann Surg. 1980; 192:9-17. [PubMed: 6447485]

228. Inokuchi K, Kobayashi M, Ogawa Y, et al. Results of left gastric vena caval shunt for esophageal varices: Analysis of one hundred clinical cases. Surgery. 1975; 78:628-636. [PubMed: 1188606]

229. Warren WD, Rudman D, Millikan W, et al. The metabolic basis of porta systemic encephalopathy and the effect of selective vs. nonselective shunts. Ann Surg. 1974; 180:573-579. [PubMed: 4416359]

230. Langer B, Rotstein LE, Stone RM, et al. A prospective randomized trial of the selective distal splenorenal shunt. Surg Gynecol Obstet. 1980; 150:45-48. [PubMed: 6965330]

231. Resnick RH, Atterbury CE, Grace ND. The Boston-New Haven Collaborative Liver Trial: Distal splenorenal shunt (DSRS) vs. portalsystemic shunt (PSS): Current status of a controlled trial. Gastroenterology. 1979; 77:A33.

232. Maillard JN, Flamant YM, Hay JM, et al. Selectivity of the distal splenorenal shunt. Surgery. 1979; 86:663-671. [PubMed: 315102]

233. Vang J, Simert G, Hansson JA, et al. Results of a modified distal splenorenal shunt for portal hypertension. Ann Surg. 1977; 185:224-228. [PubMed: 300005] 
234. Widrich WC, Robbins AH, Johnson WC, et al. Long-term follow-up of distal splenorenal shunts: Evaluation by arteriography, shuntography, transhepatic portal venography and cinefluorography. Radiology. 1980; 134:341-345. [PubMed: 7352211]

235. Warren WD. Control of variceal bleeding: Reassessment of rationale. Am J Surg. 1983; 145:816. [PubMed: 6600378]

236. Adamsons RJ, Butt K, Iyer S, et al. Portacaval shunt with arterialization of the portal vein by means of a low flow arteriovenous fistula. Surg Gynecol Obstet. 1978; 146:869-876. [PubMed: 653559]

237. Maillard JN, Rueff B, Prandi D, et al. Hepatic arterialization and portacaval shunt in hepatic cirrhosis: An assessment. Arch Surg. 1974; 108:315-320. [PubMed: 4813332]

238. Cohn R, Herrod C. Some effects upon the liver of complete arterialization of its blood supply. Surgery. 1952; 32:214-218. [PubMed: 14950607] 


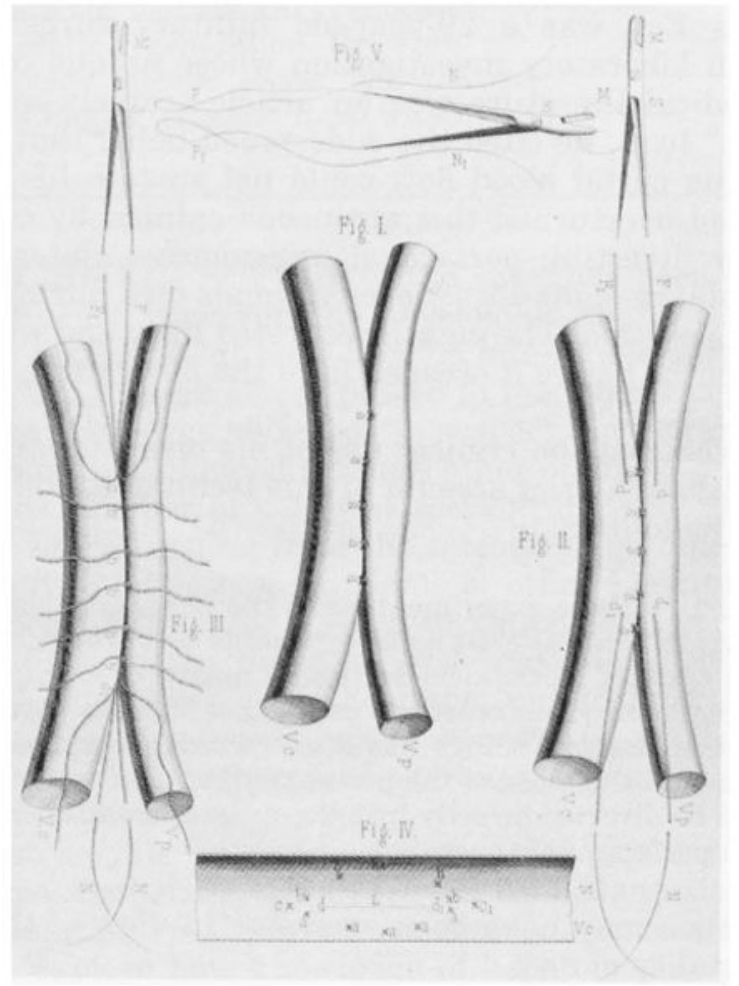

Fig 1.

The primitive technique of side-to-side portacaval anastomosis used by $\mathrm{Eck}^{3}$ and by Pavlov's group. Note that the connection between the two vessels was made by cutting or avulsing the adjacent walls inside a row of approximating simple sutures. The illustration is a photograph of the original drawing by Hahn et al. ${ }^{5}$ 


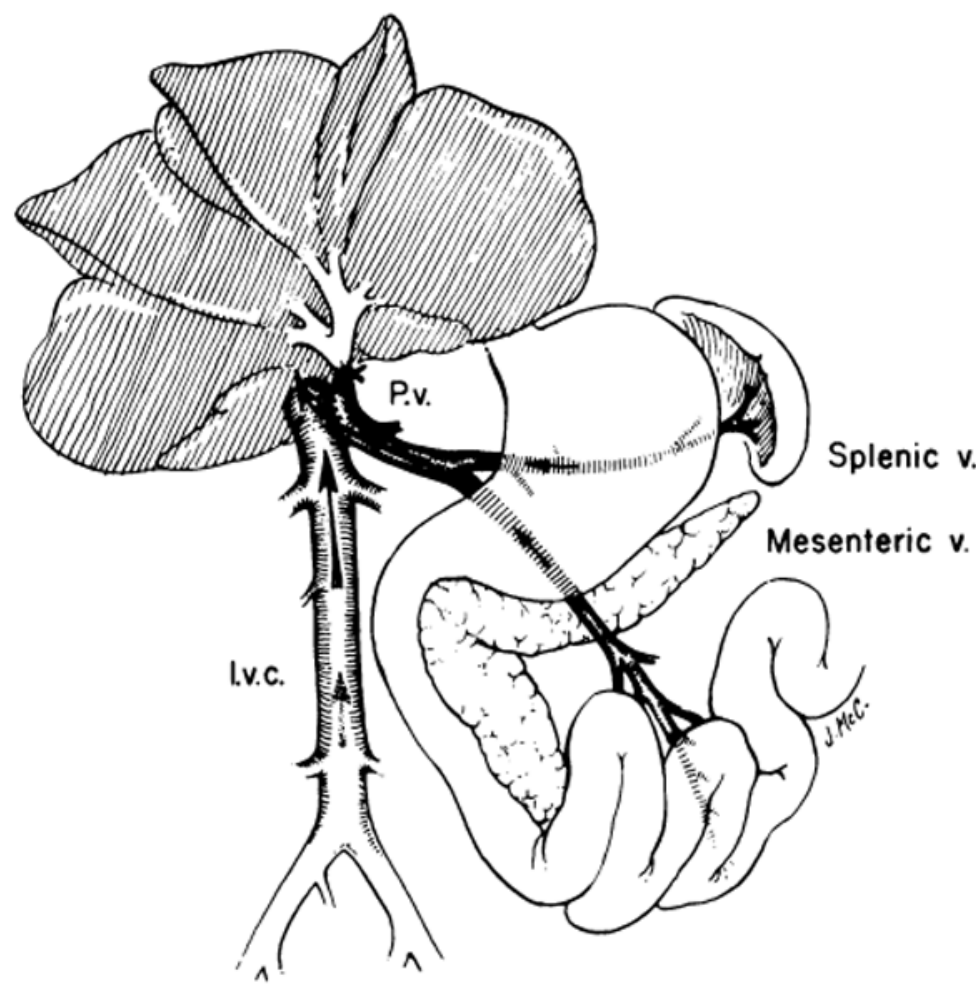

Fig 2.

Completely diverting portacaval shunt (Eck's fistula). A side-to-side anastomosis is constructed between the portal (or superior mesenteric) vein (P.v.) and the anterolateral surface of the inferior vena cava (l.v.c.). The shunt is made completely diverting by tying off the portal vein in the hilum of the liver. (From Starzl et al. ${ }^{7}$ Reproduced by permission.) 

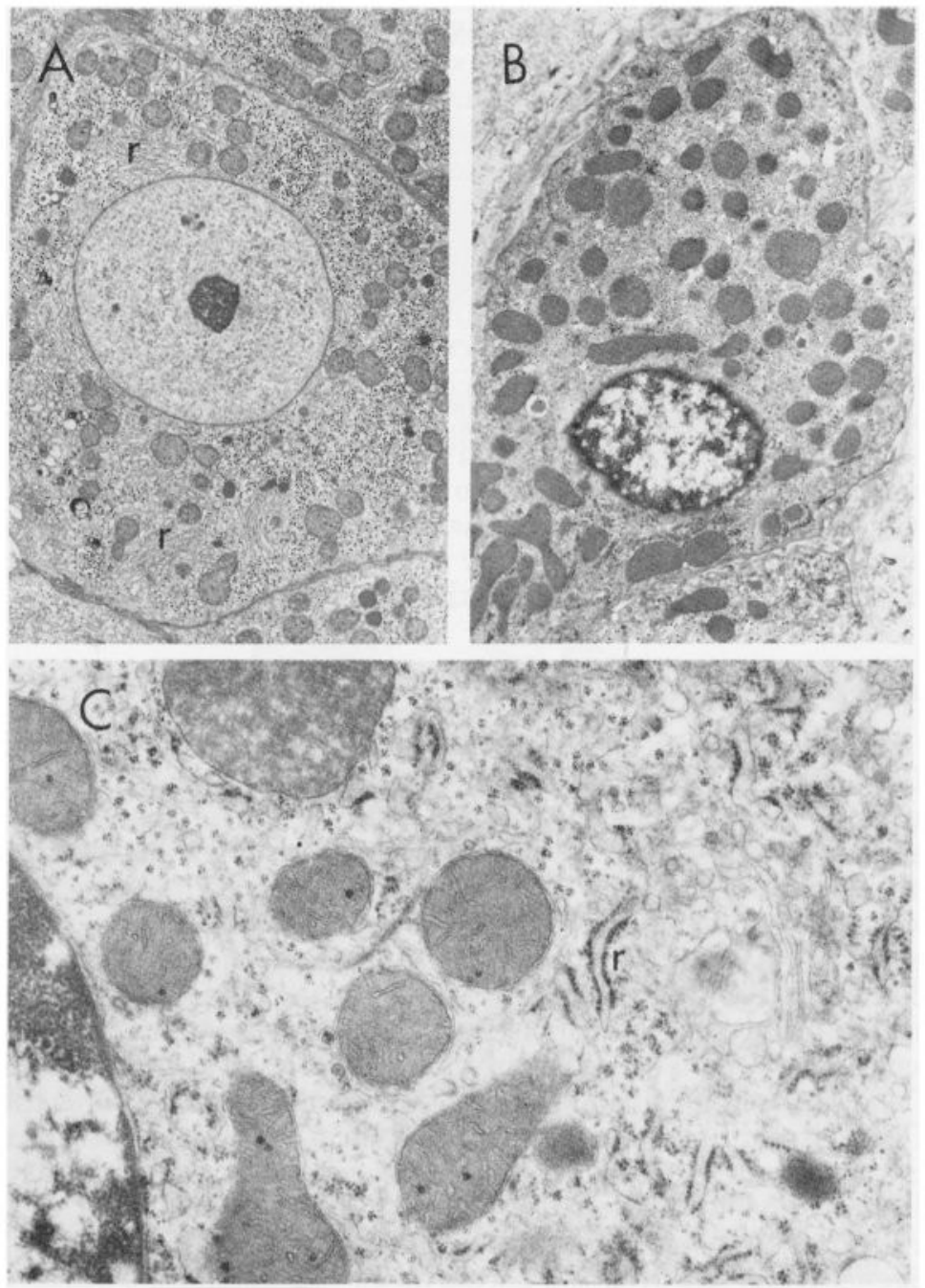

Fig 3.

Human liver biopsy appearances before (A) and after (B and $\mathbf{C})$ portacaval shunt for familial hypercholesterolemia. Rough endoplasmic reticulum $(r)$ and glycogen are abundant in the preoperative biopsy specimen. The hepatocyte is normal. Six months after portacaval anastomosis $(\mathbf{B}, \mathbf{C})$, there are major changes. Note that only isolated profiles of rough endoplasmic reticulum remain. Glycogen is absent, and there are numerous fat droplets (electron micrographs; A, $\times 3015 ; \mathbf{B}, \times 5575 ; \mathbf{C}, \times 25,100$ ). (From Starzl et al. ${ }^{20}$ Reproduced by permission.) 


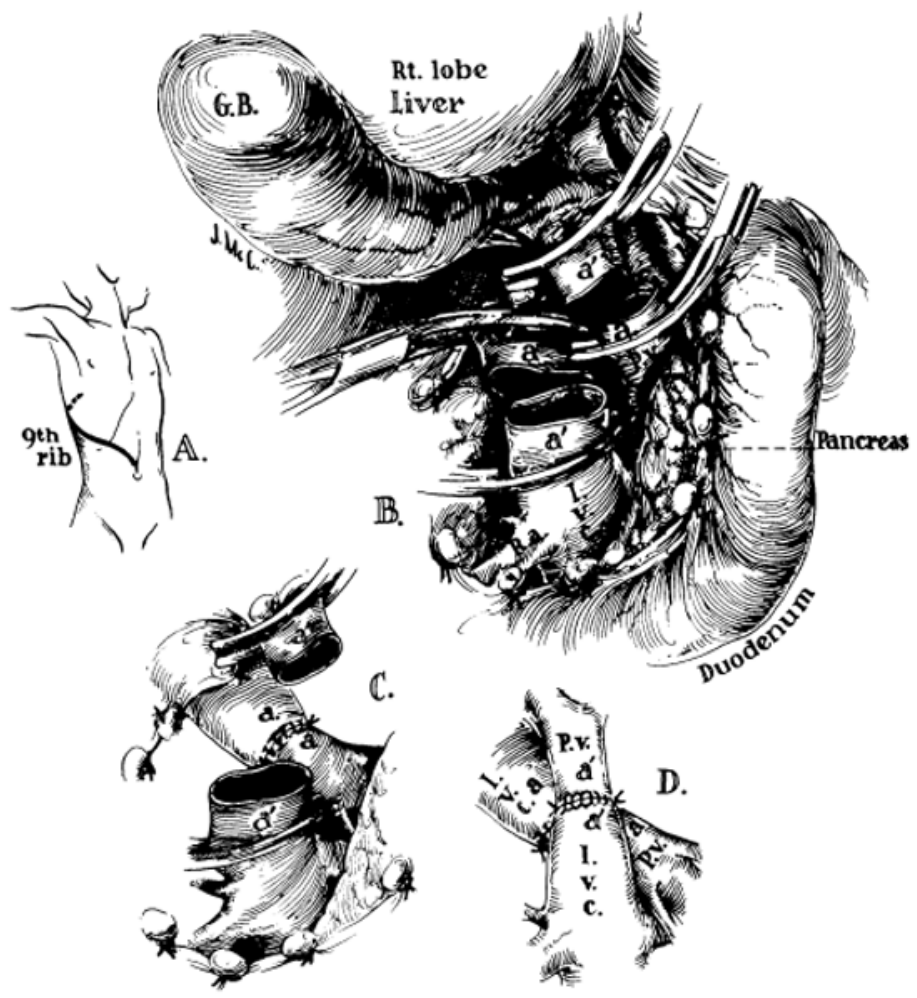

Fig 4.

The operation of portacaval transposition. The procedure is a standard laboratory experiment but it has been used clinically to treat two patients with glycogen storage disease. Note that the central portal vein is revascularized with vena caval blood. (From Starzl et al. ${ }^{28}$ Reproduced by permission.) 


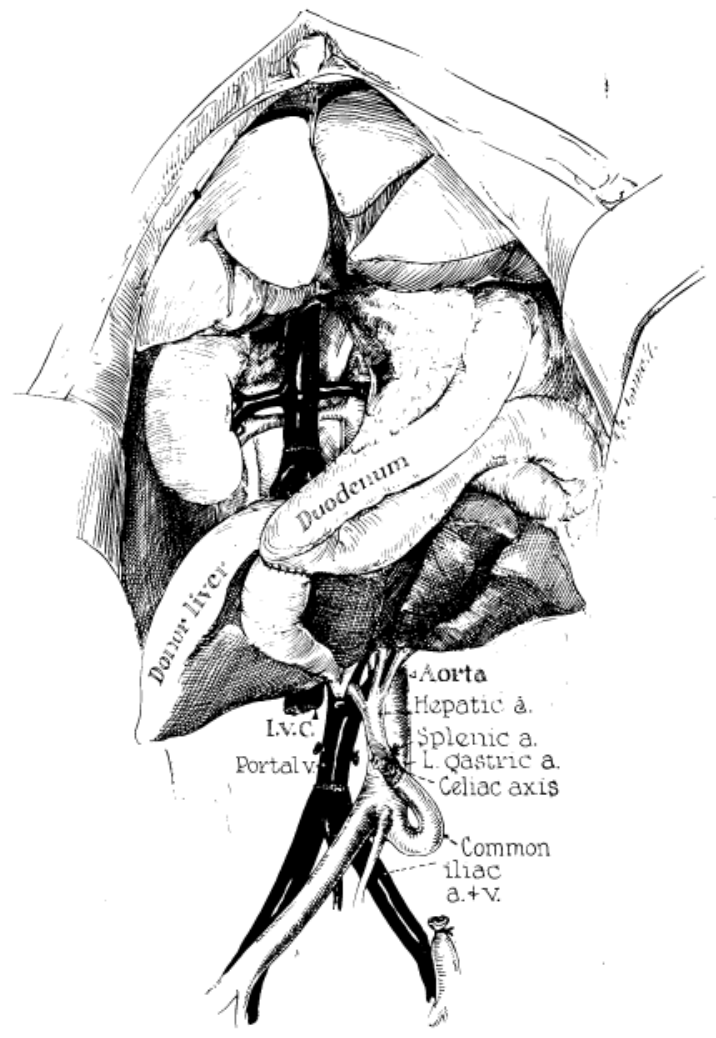

Fig 5.

Auxiliary liver transplantation in dogs by a modification of Welch's original technique. Note that the reconstituted portal blood supply is from the distal inferior vena cava. (From Starzl et al. ${ }^{30}$ Reproduced by permission.) 


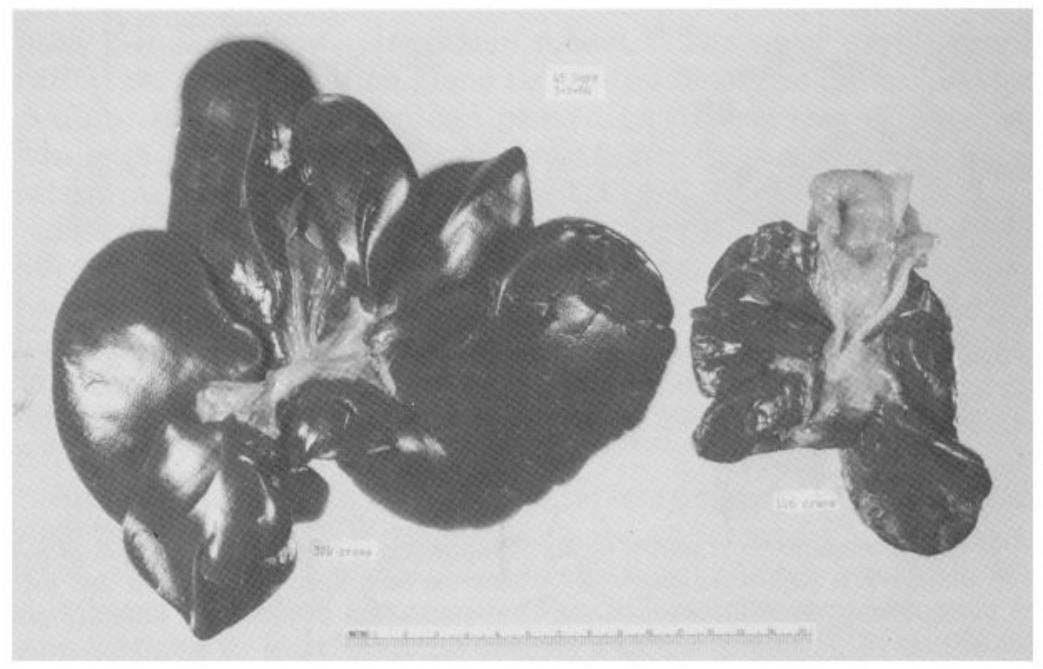

Fig 6.

An auxiliary homograft (right) and the recipient dog's own liver (left) 45 days after transplantation. Note the well-preserved but dimensionally reduced general structure of the homograft. At the time of transplantation, both the host organ and the transplant had been about the same size. (From Starzl et al. ${ }^{30}$ Reproduced by permission.) 

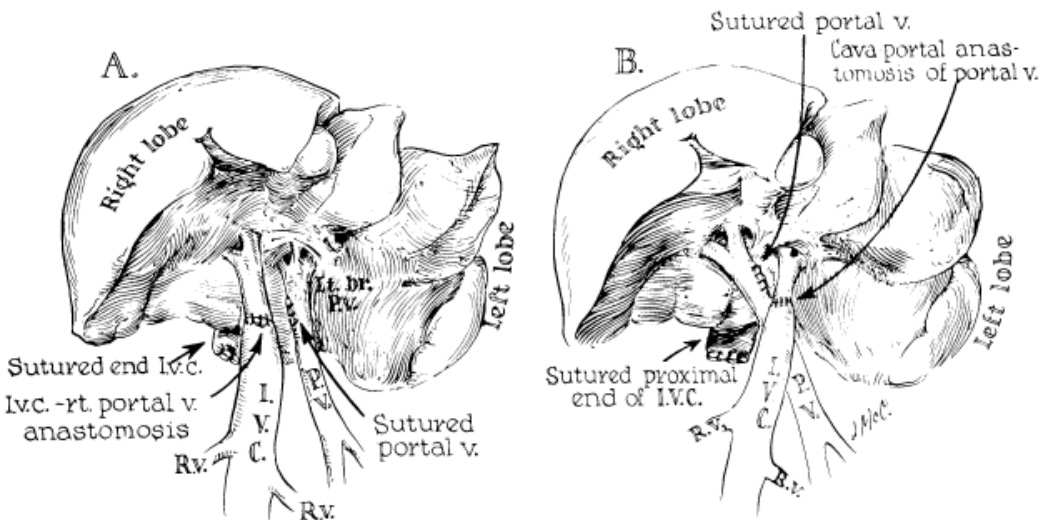

Fig 7.

The operation of partial (split) transposition in dogs. Note that one of the main portal veins (left in A, right in B) retains the natural splanchnic flow and that the other one receives the total input of the suprarenal inferior vena cava. (From Marchioro et al. ${ }^{39}$ Reproduced by permission.) 


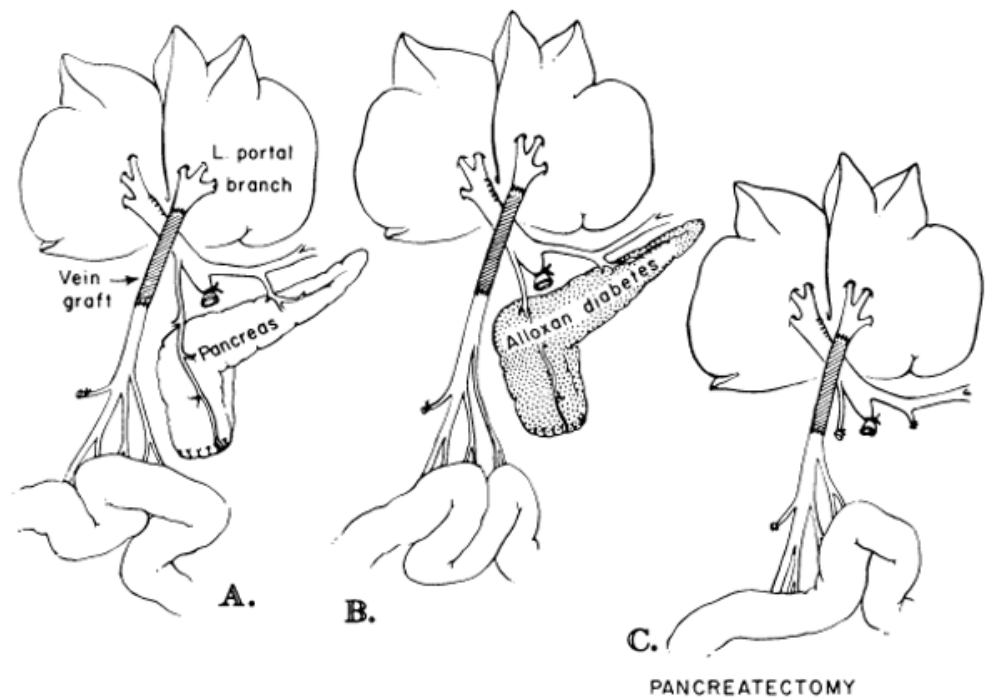

Fig 8.

Splanchnic division experiments. In these dogs, the right liver lobes received venous return from the pancreaticogastroduodenosplenic region, and the left liver lobes received venous blood from the intestines. A, nondiabetic dogs; $\mathbf{B}$, alloxan-induced diabetic dogs; $\mathbf{C}$, dogs with total pancreatectomy. (From Starzl et al. ${ }^{47}$ Reproduced by permission.) 


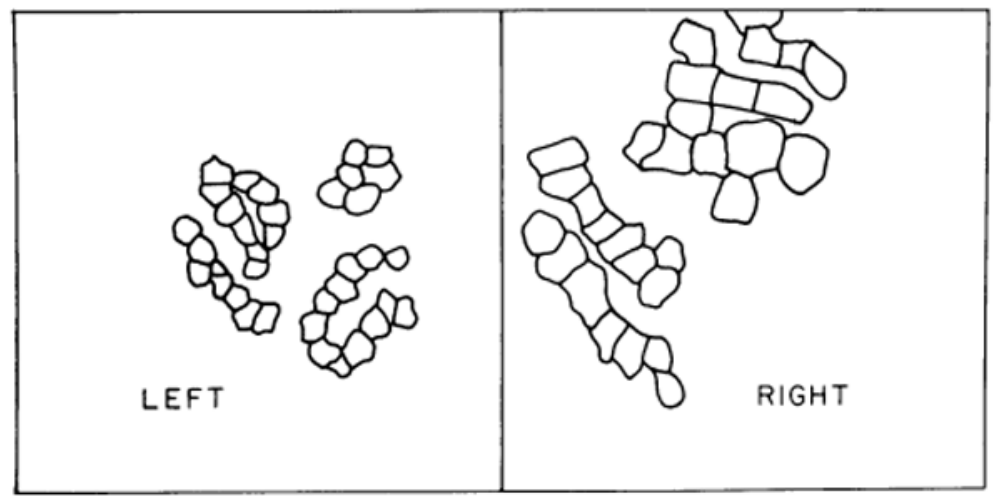

Fig 9.

Hepatocyte shadows traced during histopathologic examination. These were later cut out on standard paper and weighed as an index of hepatocyte size. The right lobes with the large hepatic cells received venous blood from the pancreas, stomach, duodenum, and spleen. The relatively shrunken left lobes with the small hepatocytes received intestinal blood. (From Starzl et al. ${ }^{45}$ Reproduced by permission.) 


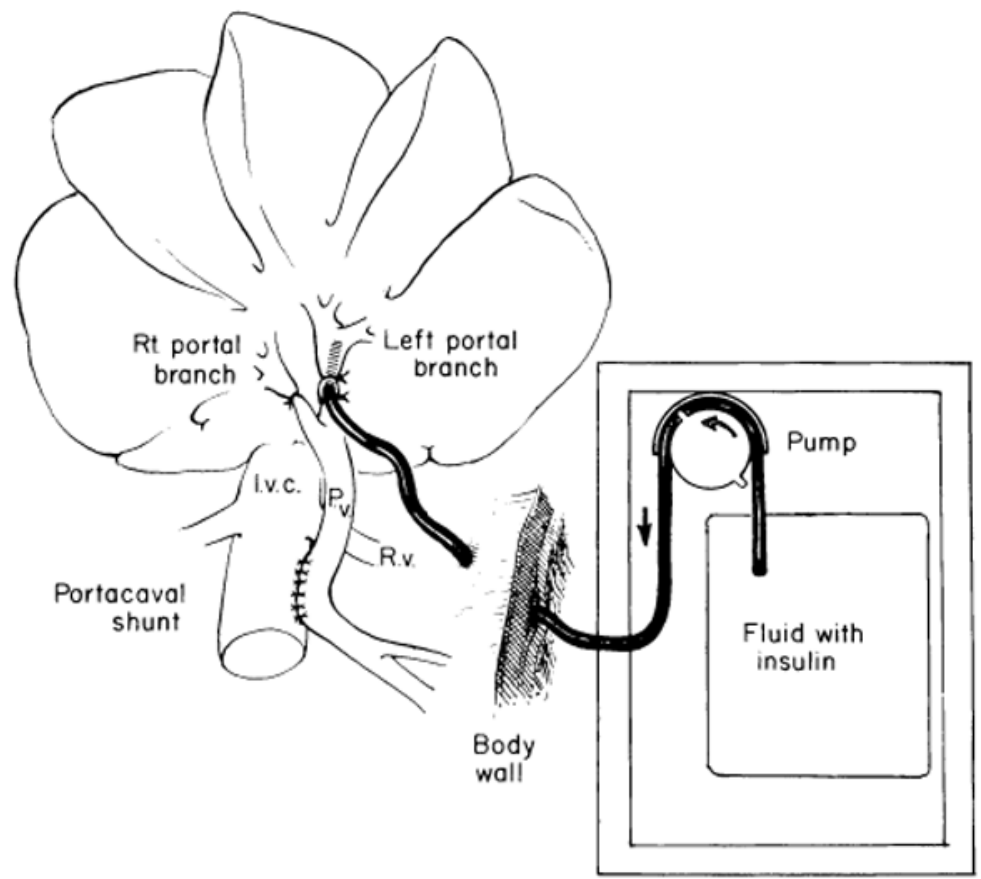

Fig 10.

Experiments in which Eck's fistula is constructed and postoperative infusions of hormones are made into the left portal vein. (From Starzl et al. ${ }^{11}$ Reproduced by permission.) 

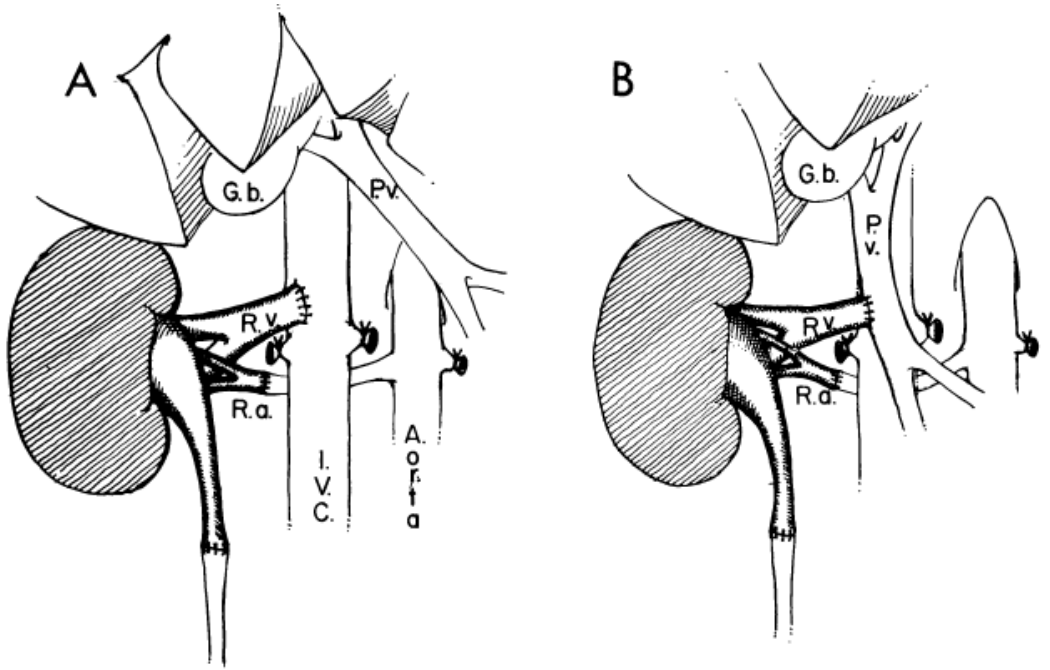

Fig 11.

Experimental models used in dogs and pigs to test the hypothesis that the liver can remove transplantation antigens. A, orthotopic renal transplantation in which the venous return was into the inferior vena cava. B, orthotopic transplantation, but venous return is into the portal vein. (From Mazzoni et al. ${ }^{110}$ Reproduced by permission.) 


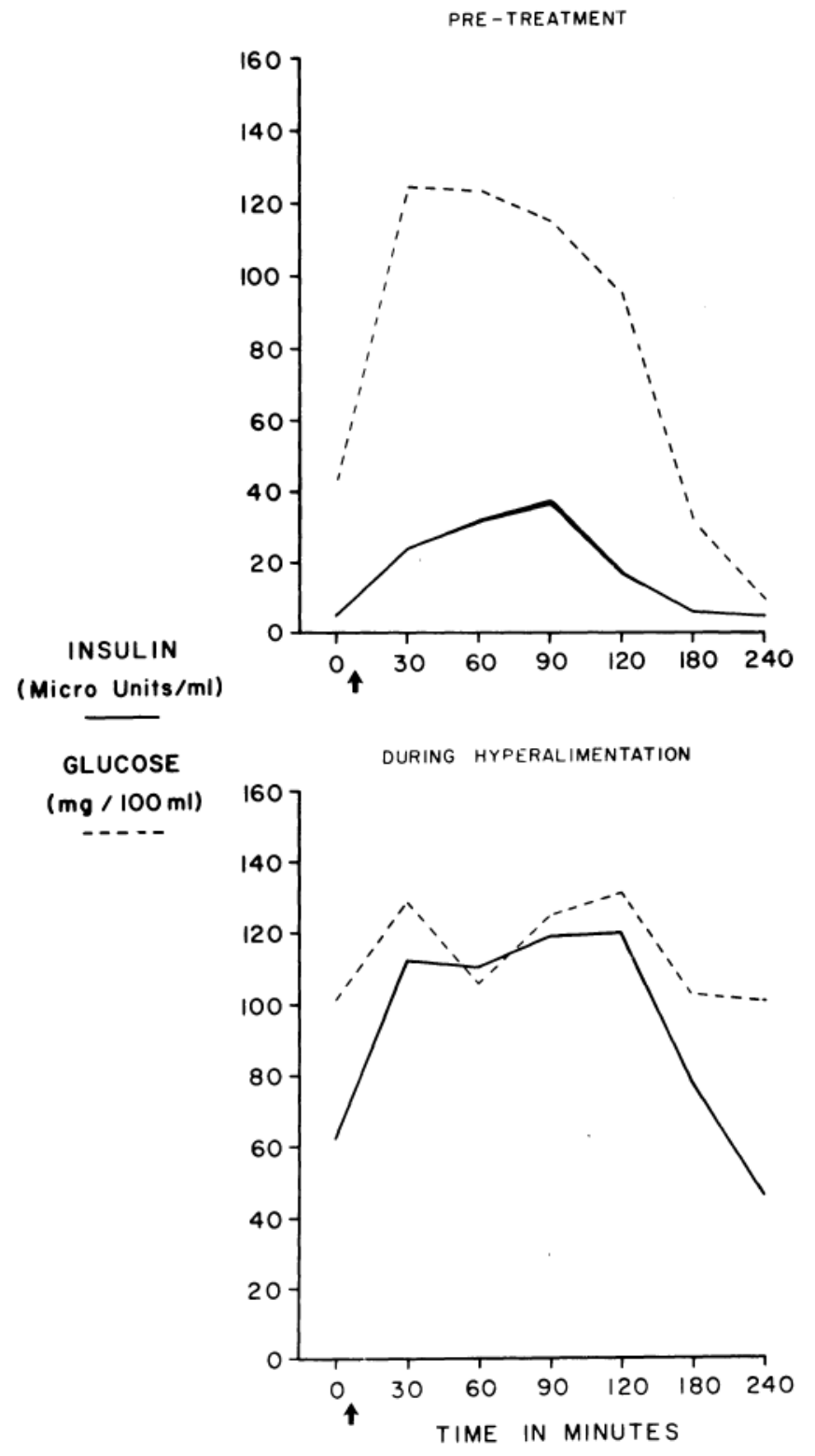

Fig 12.

Plasma insulin and glucose concentrations before and after portacaval shunt in a child with type I glycogen storage disease. (From Starzl et al. ${ }^{66}$ Reproduced by permission.) 


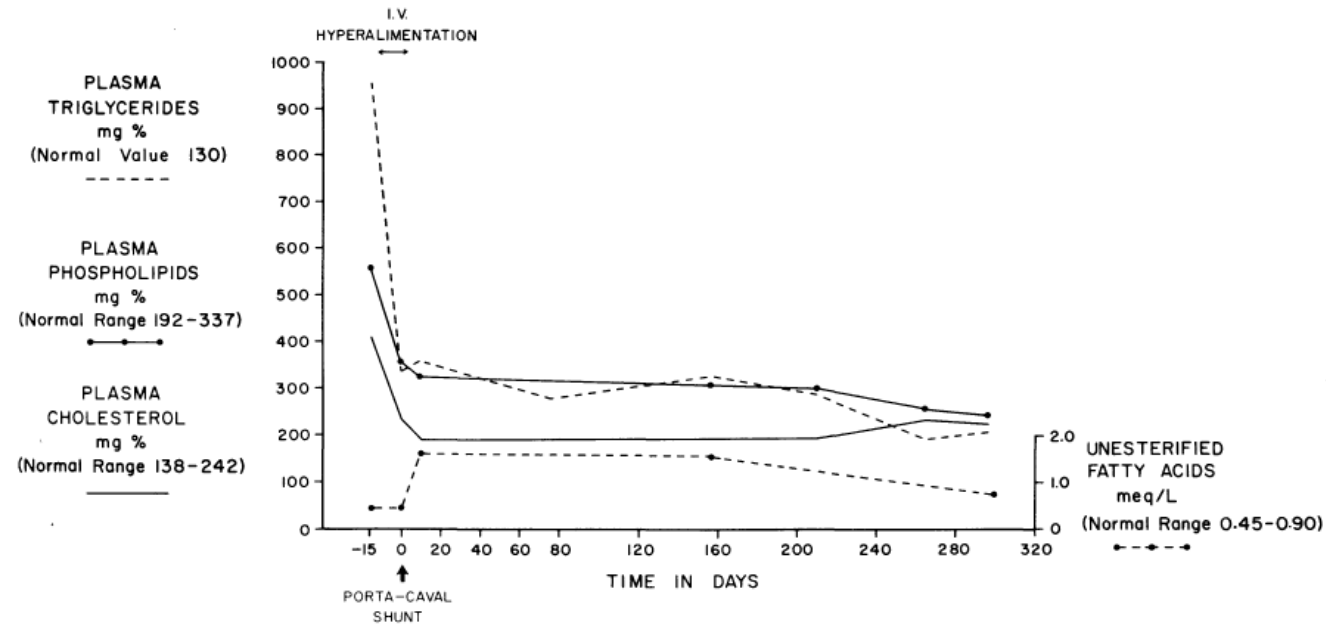

Fig 13.

Effect of parenteral hyperalimentation and end-to-side portacaval shunt on the plasma lipids of a patient with the diagnosis of type I glycogen storage disease. Note the rapid and relatively complete reversal of all abnormalities. (From Starzl et al. ${ }^{19}$ Reproduced by permission.) 

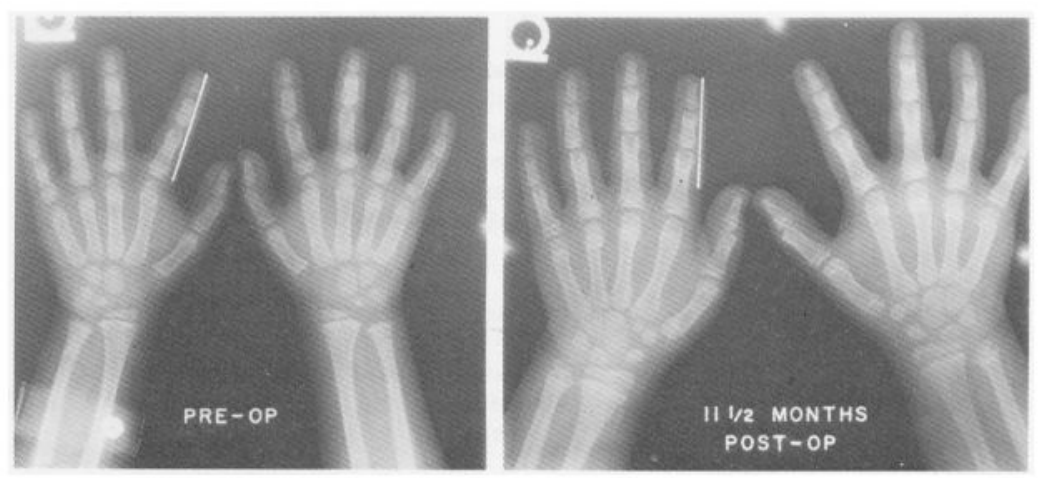

Fig 14.

The dramatic wrist and hand bone growth and mineralization in a patient with type I glycogen storage disease by $11 \frac{1 / 2}{2}$ months postoperatively. The bracket on the left index finger is $5 \mathrm{~cm}$ in length. (From Starzl et al. ${ }^{19}$ Reproduced by permission.) 


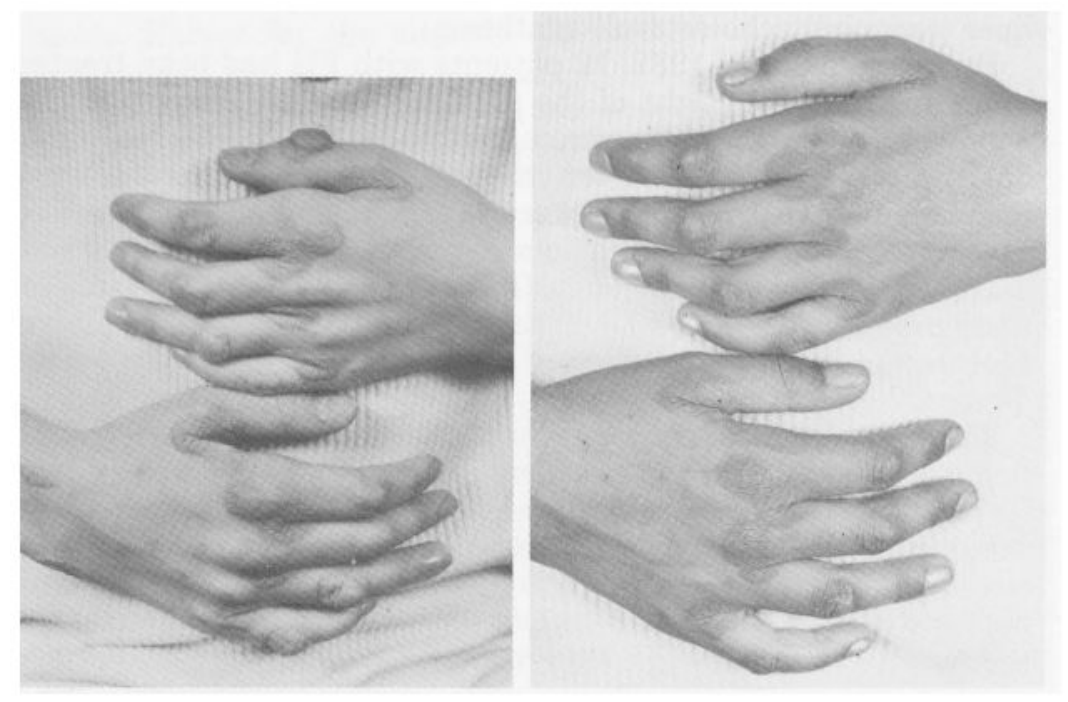

Fig 15.

The hands of a patient with hyperlipidemia 2 weeks before (left) and 16 months after (right) portacaval shunt. (From Starzl et al. ${ }^{158}$ Reproduced by permission.) 

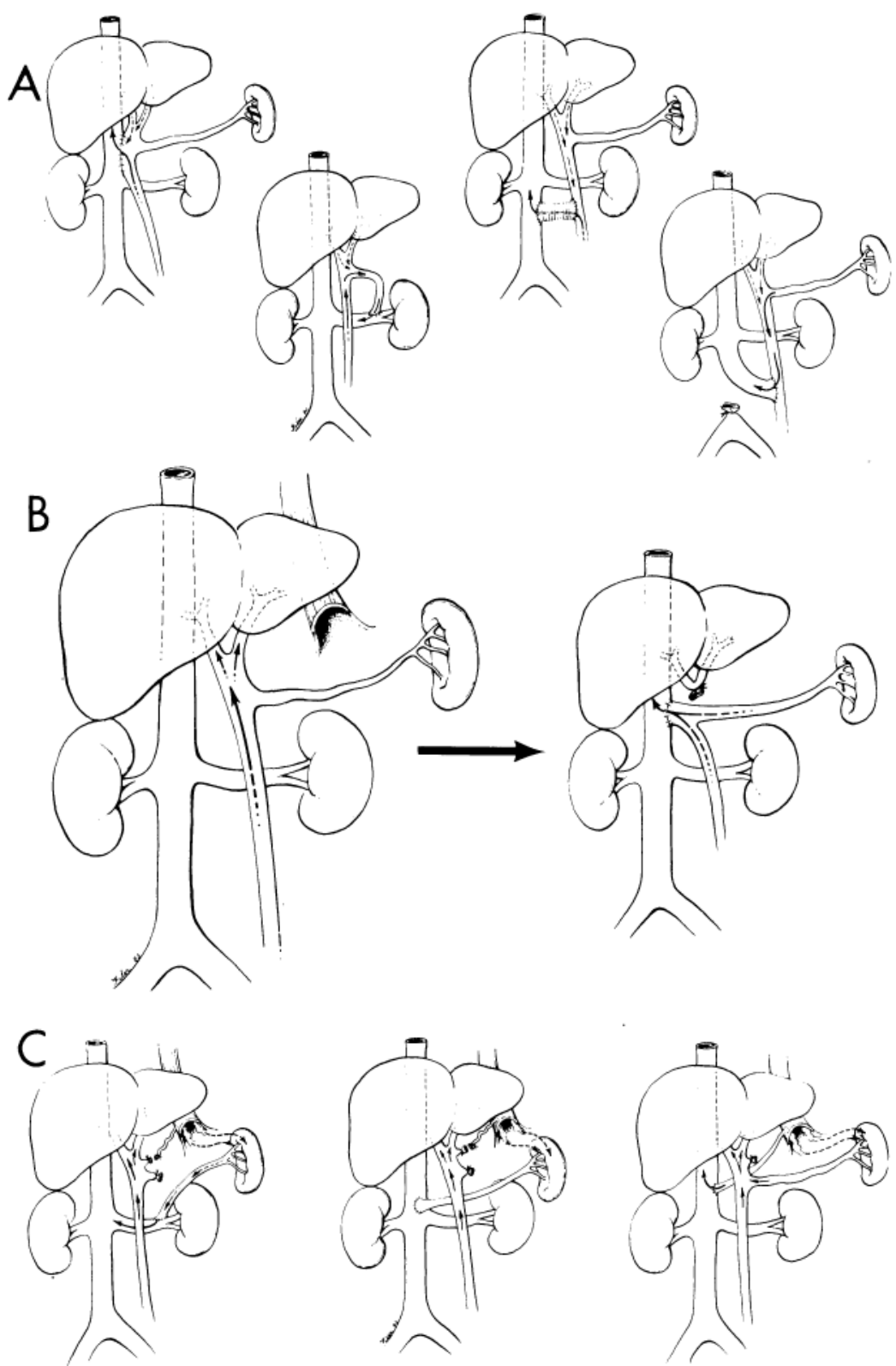

Fig 16.

Kinds of portal-systemic shunts. A, end-to-side portacaval shunt. B, variety of side-to-side shunts. C, selective portal-systemic shunts. 


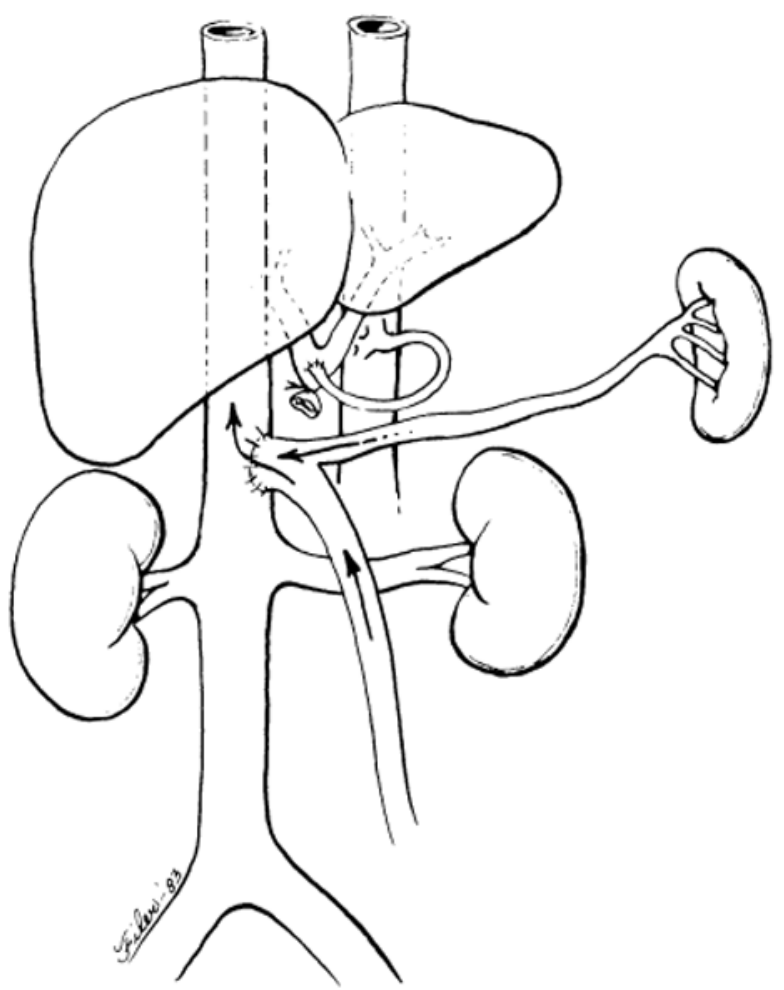

Fig 17.

End-to-side portacaval shunt, combined with arterialization of the tied-off central portal vein. 
TABLE 2

Growth Rate and Complications After Portal Diversion for Glycogen Storage Disease

\begin{tabular}{ccl}
\hline PATIENT & $\begin{array}{c}\text { GROWTH RATE }(\mathbf{c m} / \mathbf{m o . ~ o v e r ~ 4 0 - 1 2 0} \\
\text { mo. })\end{array}$ & COMPLICATIONS \\
\hline 1 & 0.49 & \\
2 & Operative death & \\
3 & 0.50 & Macroadenomatosis \\
4 & 0.28 & Died 43 / years after shunt; primary pulmonary hypertension, $\mathrm{NH}_{3}=85$, \\
& macroadenomatosis \\
5 & 0.53 & Renal artery stenosis surgically corrected 32 months after shunt \\
6 & 0.62 & \\
7 & 0.50 & \\
8 & 0.49 & Macroadenomatosis; liver transplantation after $81 / 2$ years \\
9 & 0.88 & Renal stone 2 months after shunt; mild arterial hypertension, macroadenomatosis \\
10 & 0.4 & Growth cessation after 2 years \\
Mean & 0.54 & \\
\hline
\end{tabular}

